\title{
Surfactants tailored by the class Actinobacteria
}

\author{
Johannes H. Kügler ${ }^{1 *}$, Marilize Le Roes-Hill ${ }^{2}$, Christoph Syldatk ${ }^{1}$ and Rudolf Hausmann ${ }^{3}$ \\ ${ }^{1}$ Technical Biology, Institute of Process Engineering in Life Sciences, Karlsruhe Institute of Technology, Karlsruhe, Germany, \\ ${ }^{2}$ Biocatalysis and Technical Biology Research Group, Institute of Biomedical and Microbial Biotechnology, Cape Peninsula \\ University of Technology, Bellville, South Africa, ${ }^{3}$ Bioprocess Engineering, Institute of Food Science and Biotechnology, \\ University of Hohenheim, Stuttgart, Germany
}

OPEN ACCESS

Edited by:

Pattanathu K. S. M. Rahman,

Teesside University, UK

Reviewed by:

Toru Matsui,

University of the Ryukyus, Japan

Wael Ismail,

Arabian Gulf University, Bahrain

*Correspondence:

Johannes H. Kügler,

Section II: Technical Biology, Institute

of Process Engineering in Life

Sciences, Karlsruhe Institute of

Technology, Engler-Bunte-Ring 1 ,

76131 Karlsruhe, Germany

johannes.kuegler@kit.edu

Specialty section:

This article was submitted to Microbiotechnology, Ecotoxicology and Bioremediation, a section of the

journal Frontiers in Microbiology

Received: 23 January 2015 Accepted: 02 March 2015

Published: 19 March 2015

Citation:

Kügler JH, Le Roes-Hill M, Syldatk C and Hausmann $R$ (2015) Surfactants tailored by the class Actinobacteria.

Front. Microbiol. 6:212

doi: 10.3389/fmicb.2015.00212
Globally the change towards the establishment of a bio-based economy has resulted in an increased need for bio-based applications. This, in turn, has served as a driving force for the discovery and application of novel biosurfactants. The class Actinobacteria represents a vast group of microorganisms with the ability to produce a diverse range of secondary metabolites, including surfactants. Understanding the extensive nature of the biosurfactants produced by actinobacterial strains can assist in finding novel biosurfactants with new potential applications. This review therefore presents a comprehensive overview of the knowledge available on actinobacterial surfactants, the chemical structures that have been completely or partly elucidated, as well as the identity of the biosurfactant-producing strains. Producer strains of not yet elucidated compounds are discussed, as well as the original habitats of all the producer strains, which seems to indicate that biosurfactant production is environmentally driven. Methodology applied in the isolation, purification and structural elucidation of the different types of surface active compounds, as well as surfactant activity tests, are also discussed. Overall, actinobacterial surfactants can be summarized to include the dominantly occurring trehalose-comprising surfactants, other non-trehalose containing glycolipids, lipopeptides and the more rare actinobacterial surfactants. The lack of structural information on a large proportion of actinobacterial surfactants should be considered as a driving force to further explore the abundance and diversity of these compounds. This would allow for a better understanding of actinobacterial surface active compounds and their potential for biotechnological application.

Keywords: biosurfactant, emulsifier, glycolipid, lipopeptide, trehalose lipid, Rhodococcus, rhamnolipid

\section{Microbial Surfactants and their Applications}

Microbially derived compounds that share hydrophilic and hydrophobic moieties, and that are surface active, are commonly referred to as biosurfactants. Many have been detected and described, and the majorityare molecules of low molecular weight. Within this group of low molecular weight microbial surfactants, the classes of lipopeptides or glycolipids, where fatty acid or hydroxy fatty acid chains are linked to either peptides or carbohydrates, have been extensively studied (Hausmann and Syldatk, 2014). The combinations of different types of hydrophilic and hydrophobic moieties within surfactants are innumerable and highly biodiverse. 
Due to their amphiphillic structures, surfactants act as emulsifying agents, resulting in low surface tensions of interphases. Often, microorganisms produce them when growing on hydrophobic carbon sources or when exposed to growth limiting conditions. It is hypothesized, that biosurfactants play a role in the uptake of various hydrophobic carbon sources thus making nutrients bioavailable, as well as the protection of bacteria from harsh environmental conditions (Ristau and Wagner, 1983; Vollbrecht et al., 1998; Philp et al., 2002). Some biosurfactants show antimicrobial effects and the distinction of secondary metabolites as antibiotics or biosurfactants is often not strict.

Biosurfactants, compared to chemically derived surfactants, are independent of mineral oil as a feedstock, they are readily biodegradable and can be produced at low temperatures. Furthermore, they are described to be less toxic, effective at low concentrations and show effects in bioremediation. Industrial interest in biosurfactants is not solely based on the bio-acitivity of these molecules, but is also due to the broader ecological awareness linked to their application, which in turn is driven by sustainability initiatives and green agendas (Marchant and Banat, 2012). Biosurfactants can be applied in various areas such as the nutrient-, cosmetic-, textile-, varnish-, pharmaceutical-, mining-, and oil recovery industries (Henkel et al., 2012; Marchant and Banat, 2012; Müller et al., 2012).

An example of an actinobacterial biosurfactant that has already entered the market and found industrial application, is the lipopeptide antibiotic daptomycin. This antibiotic is used in the treatment of diseases caused by Gram positive pathogens and has been marketed as Cubicin ${ }^{\circledR}$ by Cubist Pharmaceuticals.
Other promising studies for the potential application of actinobacterial biosurfactants are in environmental applications such as bioremediation: Oil spills were successfully dispersed by biosurfactants produced by a Gordonia sp. (Saeki et al., 2009), a Dietzia sp. (Wang et al., 2014) and a Rhodococcus sp. (Kuyukina and Ivshina, 2010); and trehalose lipids were applied in microbial enhanced oil recovery and the cleaning of oil storage tanks (Franzetti et al., 2010). In medical applications, the production of biosurfactants are generally considered safer than synthetically produced compounds due to high enzymatic precision during synthesis. Antiproliferation activities of cancerogenic cells could be induced by application of various glycolipids (Isoda et al., 1997; Sudo et al., 2000). In cosmetic applications, the use of trehalose lipids is favored above that of sodium dodecyl sulfate as it causes less irritation (Marques et al., 2009).

Different types of biosurfactants or bioemulsifiers have been described to be produced as secondary metabolites within the class Actinobacteria, and to the best of our knowledge, all of the producing species belong to the order Actinomycetales (Figure 1). The following section of the review will focus on the different types of actinobacterial biosurfactants reported in literature as well as their key structural features and bio-activities.

\section{Metabolite Production within the Class Actinobacteria}

Over the past few decades, there has been an increased interest in the discovery of bioactive metabolites with novel bioactive

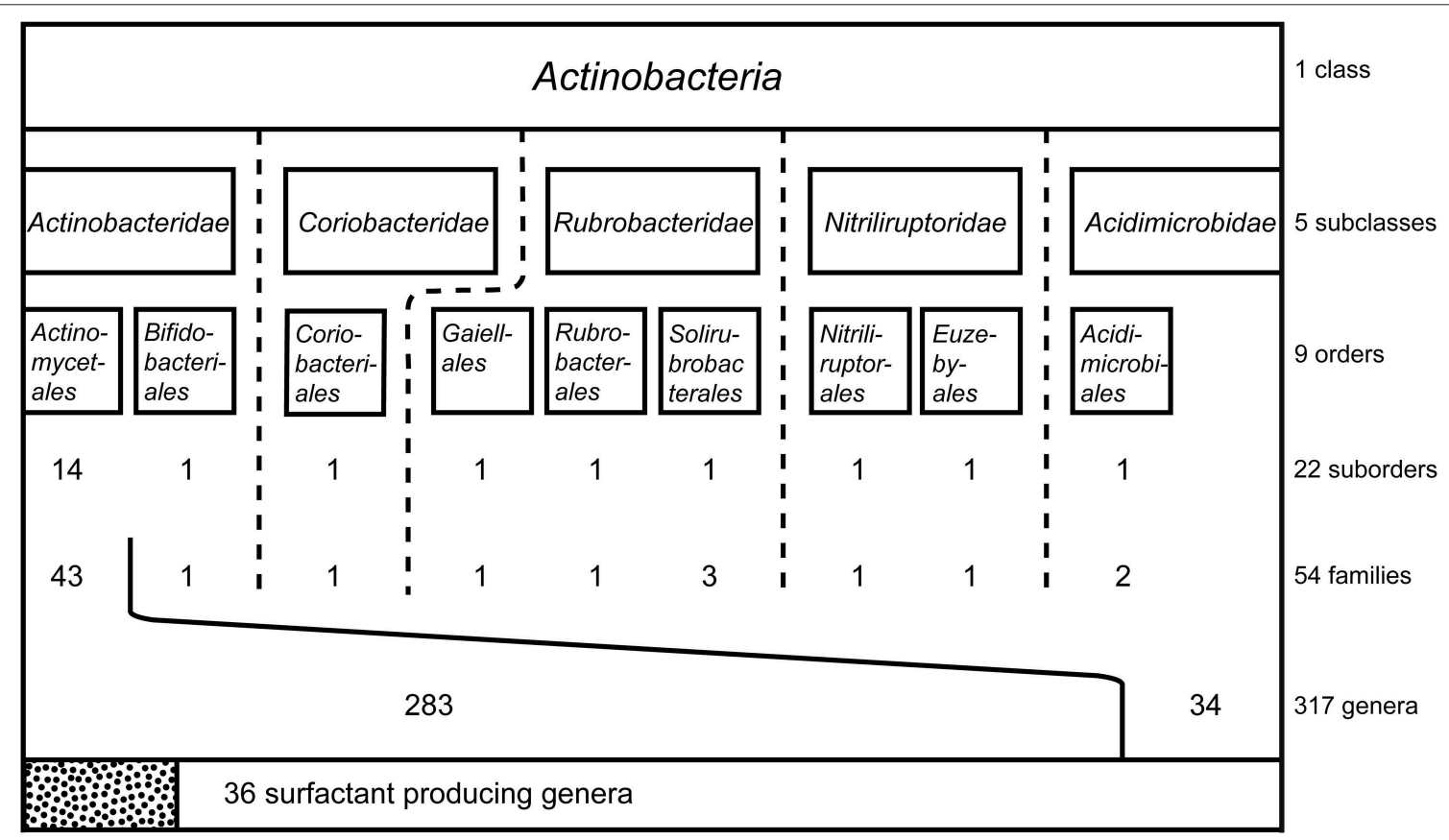

FIGURE 1 | Systematic classification of the class Actinobacteria including subclasses and orders. Suborder, families and genera examined for the production of biosurfactants and bioemulsifying compounds are displayed in numbers. Thirty six surfactant-producing genera are reported, all belonging to the largest order within the Actinobacteria: Actinomycetales. 
properties and their potential for application in medical- or industrial-based processes. Microbial products are still considered to be the most promising source for the discovery of novel chemicals or therapeutic agents (Berdy, 2005). In addition, vast microbial genetic resources remains untapped and can lead to the development of novel bioactive metabolites.

In contrast to primary metabolites, secondary metabolites often accumulate and have miscellaneous chemical compositions that are species-specific. These secondary metabolites often exhibit bioactivity and are therefore of great interest to various industries. The most dominant source of microbially derived bioactive compounds is a group of bacteria known to have relatively large genomes and constitutes one of the main phyla within the Prokaryotes: The class Actinobacteria (Ludwig and Klenk, 2001). The class Actinobacteria play important roles in the environment, e.g., nutrient cycling, but also include major plant, animal and human pathogens (Embley and Stackebrandt, 1994), well known examples are the causative agents of leprosy and tuberculosis. Baltz (2008) assumed $5-10 \%$ of their genome coding capacity to be used for the production of secondary metabolites and indeed more than $35 \%$ of all known bioactive microbial metabolites and more than $63 \%$ of all known prokaryotic bioactive metabolites arise from actinobacteria (Bérdy, 2012). Most secondary metabolite producers described belong to families of the Actinomycetales, but it is estimated that only $\sim 1 \%$ of them are culturable (Bérdy, 2012). Many of these actinobacterial secondary metabolites exhibit antibacterial, antifungal, antitumor, anticancer and/or cytotoxic properties (Manivasagan et al., 2013). Antibiotics, with around 10,000 compounds described (Bérdy, 2012) is by far the largest group of metabolites isolated from actinobacteria. Depending on their chemical nature, the huge number of antibiotic compounds can roughly be classified into peptides, aminoglycosides, polyketides, alkaloids, fatty acids, and terpenes (Manivasagan et al., 2013; Abdelmohsen et al., 2014). Besides antibiotics, other actinobacterial compounds described are bioactive compounds with pharmacological activity (pheromones, toxins, enzyme inhibitors, receptors and immunological modulators), with agricultural activity (pesticides, herbicides and insecticides) and other industrially relevant properties (pigments and surfactants). Most compounds are derived from members of the genus Streptomyces, however, other so-called "rare" actinomycetes are increasingly playing a more important role in the production of biocompounds (Berdy, 2005; Kurtboke, 2010).

To fully understand the taxonomic distribution of the actinobacterial strains identified to produce biosurfactants and bioemulsifying compounds, taxonomic data of the class Actinobacteria was evaluated. Information were retrieved from the taxonomy browser of the National Center for Biotechnology Information $^{1}$ considering $16 \mathrm{~S}$ rRNA gene sequence based reclassifications according to Zhi et al. (2009) and Goodfellow and Fiedler (2010). The order Thermoleophilales that has been reclassified into a new class (Euzéby, 2013) has been excluded and the

${ }^{1}$ National Center for Biotechnology Information (NCBI) Taxonomy Browser. Available online at: http://www.ncbi.nlm.nih.gov/Taxonomy/ Browser/wwwtax.cgi? mode $=$ Undef\&id=201174\&lvl=5\&lin $($ accessed 01.07.2014 07.01.2015) recently identified order Gaiellales has been included (Euzéby, 2012). Overall, the class Actinobacteria contains five subclasses and nine orders with a total of 54 families (Figure 1). The largest order, Actinomycetales, is divided into 14 suborders and contains by far the highest diversity within the class Actinobacteria. It is therefore not surprising that biosurfactants reported in literature focuses on members of this order. The next few paragraphs will go into more detail around the different types of biosurfactants that have been identified to be produced by actinobacterial strains, their production, purification and structural elucidation, as well as the clear influence of the environment the producer organism is found in and their ability to produce biosurfactants.

\section{Trehalose-Comprising Glycolipids}

The best described biosurfactants amongst the actinobacteria are glucose-based glycolipids, most of which have a hydrophilic backbone consisting of two $\alpha, \alpha-1,1$ glycosidic linked glucose units forming a trehalose moiety. Different types of trehalosecontaining glycolipids and their producers have been extensively reviewed (Asselineau and Asselineau, 1978; Asselineau and Lanéelle, 1998; Franzetti et al., 2010; Kuyukina and Ivshina, 2010; Shao, 2011; Khan et al., 2012). Those of the class Actinobacteria are mainly found within the genera Rhodococcus, Mycobacterium, Nocardia, Arthrobacter and Corynebacterium, and less frequently within the genera Tsukamurella, Brevibacterium, and Micrococcus (Tables 1, 2). Different structures of trehalose lipid comprising amphiphilic molecules have been reported: Acyl chains with glycosidic linkages to glucose or trehalose units have been reported to vary in number of occurrence, length and type, as well as the position (and number) of their linkage to the sugar rings and exhibit different cellular functions.

For the hydrophobic moiety of trehalose-comprising glycolipids, the structures of two main types of trehalose lipids have been elucidated: those carrying a mycolic fatty acid ester and those carrying a fatty acid ester.

The smallest hydrophilic backbone in glycolipids constitutes glucose, the building block of the sugar dimer trehalose. Complete structures of acylglucoses carrying mycolic acid esters have been elucidated and reported to be produced by isolates belonging to the genera Corynebacterium and Mycobacterium (Brennan et al., 1970) (Table 1), whereas acylglucoses carrying fatty acid esters have been described for Brevibacterium spp. (Okazaki et al., 1969) (Table 2).

\section{Trehalose Lipid Mycolic Acid Esters}

Mycolic acids are long-chain fatty acids and a major component of the cell wall in various actinobacteria. Species-dependent, its lengths varies from 22 to 92 carbon atoms; they possess long $\beta$-hydroxy- $\alpha$-branched acyl chains, including cyclopropane patterns and oxygenic groups. The synthesis of mycolic acids includes condensation reactions, and they are also referred to as eumycolic acid, corynemycolic acid and nocardio-mycolic acid, depending on their presence in Mycobacterium spp., Corynebacterium spp., and Nocardia spp., respectively (Asselineau and Lanéelle, 1998). 
TABLE 1 | Mycolic and corynemycolic containing trehalose lipids that are of actinobacterial origin.

\begin{tabular}{|c|c|c|c|}
\hline Species & Strain & TL mycolic acid ester & References \\
\hline Arthrobacter paraffineus & KY 4303 & TL mycolic (C32-C36) & Suzuki et al., 1969 \\
\hline Brevibacterium sp. & KY 4304/4305 & TL mycolic (C32-36) & Suzuki et al., 1969 \\
\hline Corynebacterium diphtheriae & n.a. & Glucose mycolic (C32) & Brennan et al., 1970 \\
\hline $\begin{array}{l}\text { Corynebacterium spp. } \\
\text { (fasciens, pseudodiphtheriae) }\end{array}$ & $\begin{array}{l}\text { KY } 3543 \\
\text { KY } 3541\end{array}$ & TL mycolic (C32-36) & Suzuki et al., 1969 \\
\hline $\begin{array}{l}\text { Mycobacterium spp. } \\
\text { (smegmatis, tuberculosis) }\end{array}$ & BCG, n.a. & Glucose mycolic (C32) & Brennan et al., 1970 \\
\hline $\begin{array}{l}\text { Mycobacterium spp. } \\
\text { (bovis, fortuitum, kansaii, malmoense, phlei, } \\
\text { tuberculosis, smegmatis, szulgai, etc.) }\end{array}$ & Various & TL mycolic, dimycolic, & $\begin{array}{l}\text { Reviewed in: Asselineau and Asselineau, 1978; Gautier } \\
\text { et al., 1992; Asselineau and Lanéelle, 1998; Vergne and } \\
\text { Daffé, 1998; Dembitsky, 2004; Ishikawa et al., 2009; } \\
\text { Shao, 2011 }\end{array}$ \\
\hline
\end{tabular}

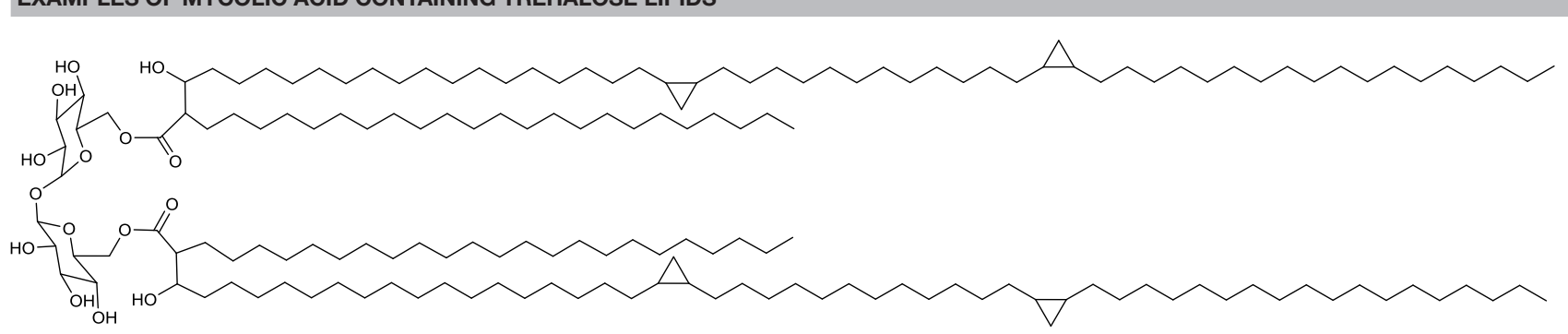

1

Trehalose dimycolate produced by Mycobacterium tuberculosis

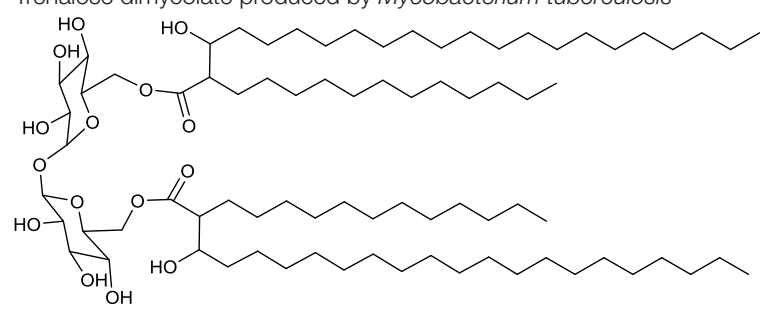

2

Trehalose dicorynemycolate produced by Rhodococcus erythropolis

"Several producing species are reported; TL, trehalose lipid; n.a., information not available.

Mycolic acid comprising trehalose lipids (Table 1) can be distinguished into two different types, the trehalose mycolic lipids and the trehalose corynemycolic lipids. These mycobacterial trehalose mycolates or dimycolates are by far the most hydrophobic glycolipids. Linked to $\mathrm{C} 6$ (and $\mathrm{C}^{\prime}$ ) of the sugar rings, they vary among species in length and branching. They are shaped to form bilayers, implemented in the outer cell wall and usually not found on the bacterial cell surface (Vergne and Daffé, 1998). Trehalose dimycolates (1, Table 1), also referred to as "cord factor," serve a particular function for the cell. They act as virulence factors and have immuno-modulating activity (Shao, 2011). They may further be important to maintain a hydrophobic cell wall of the organism hence facilitating the uptake of hydrophobic carbon sources. The other type, trehalose lipids containing corynemycolic acid also carry $\beta$-hydroxy- $\alpha$-branched fatty acid moieties and have been described to occur within the genus Rhodococcus (2, Table 1), carrying 30-56 carbon atoms and within the genus Corynebacterium, carrying 22-36 carbon atoms. They are also described to occur in mycobacteria (Brennan et al., 1970) and found in trehalose lipids of Brevibacterium vitarumen (Lanéelle and Asselineau, 1977), Arthrobacter paraffineus and a Nocardia sp. (Suzuki et al., 1969). Corynemycolic acids are much shorter than their mycobacterial counterparts: they lack functional groups and are often unsaturated. Within virulent strains 
TABLE 2 | Trehalose lipid ester of actinobacterial origin.

\begin{tabular}{|c|c|c|c|}
\hline Species & Strain & TL ester & References \\
\hline Brevibacterium thiogenitalis & No. 653 & Glucose diester (C18) & Okazaki et al., 1969 \\
\hline $\begin{array}{l}\text { Mycobacterium spp. }{ }^{*} \\
\text { (africanum, bovis, fortuitum, tuberculosis, etc.) }\end{array}$ & Various & TL ester & $\begin{array}{l}\text { Reviewed in: Vergne and Daffé, 1998; } \\
\text { Dembitsky, 2004; Shao, } 2011\end{array}$ \\
\hline Mycobacterium tuberculosis & H37Rv & TL sulfolipid & Goren, 1970; Gilleron et al., 2004 \\
\hline Tsukamurella pulmonis & PCM 2578T & TL diester (C18-20/C4-5) & Pasciak et al., 2010a \\
\hline $\begin{array}{l}\text { Tsukamurella spumae } \\
\text { Tsukamurella pseudospumae }\end{array}$ & $\begin{array}{l}\text { DSM } 44113 \text {, } \\
\text { DSM } 44114 \\
\text { DSM } 44117\end{array}$ & TL diester (C16-18/C4-6) & Kügler et al., 2014 \\
\hline
\end{tabular}

\section{EXAMPLES OF TREHALOSE LIPID ESTERS}

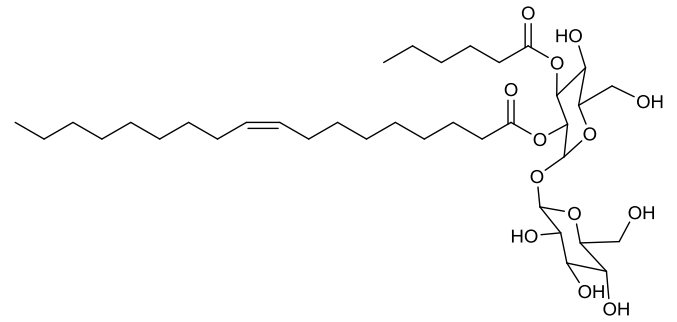

3

Trehalose diester produced by Tsukamurella spumae

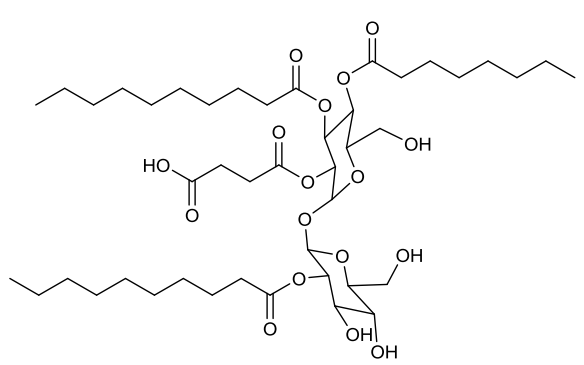

4

Succinic trehalose tetraester produced by Nocardia farcinia

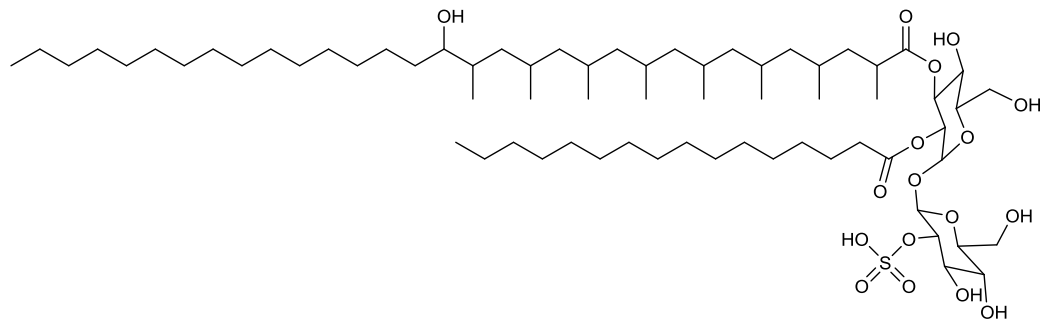

5

Diacetylated trehalose sulfolipid produced by Mycobacterium tuberculosis

"Several producing species are reported; TL, trehalose lipid.

of mycobacteria, five different sulfonated forms of trehalose esters have been found, varying in their acylation pattern (Khan et al., 2012).

\section{Trehalose Lipid Esters}

Actinobacterial trehalose lipid esters are mainly acylated at C6/C6' or at C2/C3 and are summarized in Table 2. The amount of hydrophobic chains linked to the trehalose unit varies from one to four, forming trehalose mono-, di-, tri- and tetraesters, but also octaesters (Singer et al., 1990) (3, Table 2). The acyl chains varies in lengths from C8 to C20, show an unsaturated pattern or form short succinoyl acids, giving the trehalose lipid an anionic character (Lang and Philp, 1998; Tokumoto et al., 2009) (4, Table 2). They are reported to be linked to the chain length present in hydrophobic carbon source fed to the producing strain. These glycolipid-linked medium chain length fatty acids are found within the following actinobacterial genera: Arthrobacter, Brevibacterium, Caseobacter, Micrococcus, Mycobacterium, Nocardia, Rhodococcus, and Tsukamurella (Table 2).

An exception among the trehalose lipid esters described, is sulfolipid 1 (Goren, 1970) (5, Table 2), a sulfonated and acylated trehalose lipid carrying phtio- and hydroxyphtioceranic compartments. They are known to contribute to the pathogenesis and virulence of Mycobacterium tuberculosis, the causative agent of tuberculosis. Diacyltrehalose sulfate, the biosynthetic precursor for sulfolipid 1 , has recently been isolated from $M$. tuberculosis (Domenech et al., 2004) and has been used as a target for T-cell mediated recognization and elimination of $M$. tuberculosis infected cells (Gilleron et al., 2004). 


\section{Oligosaccharide Lipids}

A glycosylated backbone of trehalose is found in oligosaccharide lipids (Table 3) carrying two to five sugar units. Trisaccharide lipids that have been reported for the class Actinobacteria all differ with respect to the acylation pattern of the third glucose unit. One sugar of the 1-1' linked di-glucose backbone is further linked to a third sugar unit at C2 in the hydrophilic moeity of oligosaccharides produced by Mycobacterium leprae (Brennan, 1989) and Tsukamurella tyrosinosolvens (Vollbrecht et al., 1998). The third sugar unit is linked at C3 in a terrestrial actinomycete reported by Esch et al. (1999) and at C4 in a Rhodococcus sp. (Konishi et al., 2014) (6, Table 3). They also differ with respect to their hydrophobic nature. The latter two are acylated at all three sugar units, both carrying a C6 fatty acid moiety at the third sugar unit and succinic acid at the first sugar unit. Something that is rather exceptional is the acylation pattern at the trehalose backbone that, in its hydrophobic moieties, carries at each unit an acyloxyacyl structure in the $\mathrm{O}$-ester linkage to the carbohydrate where the 3 hydroxy C8 or C10 fatty acid moiety is further acylated with a C6 fatty acid (6, Table 3). The Tsukamurella sp. trisaccharide lipids are acylated at two sugar units, each carrying two ordinary C8C10 fatty acid units. Furthermore, a tetrasaccharide lipid form of this glycolipid has also been found to occur (Vollbrecht et al., 1998) (7, Table 3).

Non-trehalose based oligosaccharide lipids are found within phenol-phtiocerol glycosides in various mycobacteria. These

\section{TABLE 3 | Actinobacterial oligosaccharide lipids.}

\begin{tabular}{|c|c|c|c|}
\hline Species & Strain & Oligosaccharid lipids & References \\
\hline $\begin{array}{l}\text { Mycobacterium spp. } \\
\text { (avium, kansaii, leprae, linda, malmoense, smegmatis, szulgai, } \\
\text { tuberculosis) }\end{array}$ & Various & $\begin{array}{l}\text { oligosaccharide ester, phenolic } \\
\text { glycolipids }\end{array}$ & $\begin{array}{l}\text { Reviewed in: Saadat and Ballou, } \\
\text { 1983; Brennan, 1989; } \\
\text { Dembitsky, 2005b }\end{array}$ \\
\hline Nocardia corynebacteroides & SM1 & $\begin{array}{l}\text { Pentasaccharide succinic octaester } \\
\text { (C2-C8) }\end{array}$ & Powalla et al., 1989 \\
\hline $\begin{array}{l}\text { Rhodococcus sp. } \\
\text { Rhodococcus fascians }\end{array}$ & $\begin{array}{l}\text { NBRC } 1097287 \\
\text { NBRC } 12155\end{array}$ & $\begin{array}{l}\text { Trisaccharid succinic tetraester } \\
\text { (C8-O-C6/C6) }\end{array}$ & Konishi et al., 2014 \\
\hline Tsukamurella tyrosinosolvens & DSM 44370 & Tri/tetrasaccharide ester (C8-10) & Vollbrecht et al., 1998 \\
\hline
\end{tabular}

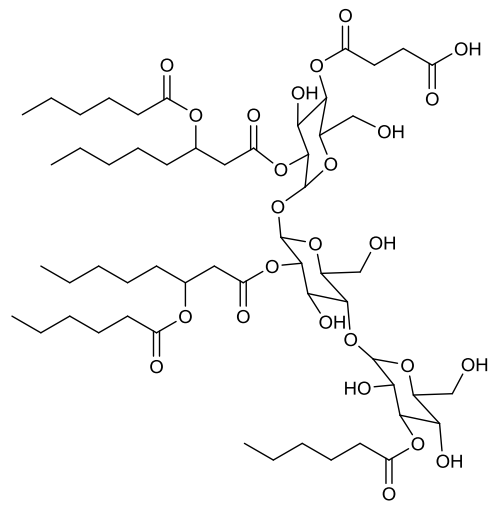

6

Succinic trisaccharide lipid produced by Rhodococcus fascians

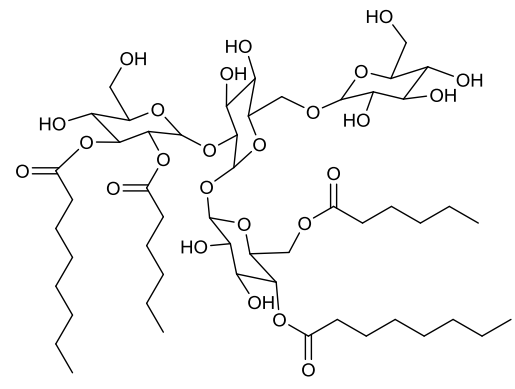

7

Tetrasaccharide lipid produced by Tsukamurella tyrosinosolvens<smiles>CCCCCCCCCCCCCCCCCCCCCCCCCCCCCCCCCCCCCCCCCCCCCCCCCCCCCCCCC(CCCCC(CC)C(CC)OC)OC(=O)C(C)CC(C)CC(C)CC(C)CC(C)CC(C)CC(C)CC(C)CC(C)CCCCCCCCCCCC(C)CC(C)CC(C)C</smiles>

8

Methylated dirhamnose/glucose phenol phtiocerol named phenolic glycolipid I of Mycobacterium leprae Brennan, 1989

\footnotetext{
"Several producing strains are reported.
} 
oligosaccharide lipids, also termed phenolic glycolipids, contain tri- and tetraglycosyl units composed of various methylated sugars that are mainly based on rhamnose and partly on fucose, glucose and arabinose (Brennan, 1989). The rarely described phenolic acylation pattern is bound to dimycocerosyl phtiocerol acyl groups. The phenolic glycolipid I of $M$. leprae carries three mycocerosyl acyl groups each in length of C30-C34 (Brennan, 1989) (8, Table 3).

In industrial and environmental processes the potential of trehalose lipids could become valuable as they have shown interesting properties in several studies that focus on the remediation of hydrocarbon contaminated soils, the removal of suspended solids from wastewater (Franzetti et al., 2010) and in enhanced oil recovery (Christofi and Ivshina, 2002). However, most research are centered around the bio-activity of trehalose lipid molecules that exhibit biomedical properties such as antimicrobial, antiviral (Azuma et al., 1987; Watanabe et al., 1999; Shao, 2011) and antitumor activities (Sudo et al., 2000; Franzetti et al., 2010; Gudiña et al., 2013). Due to their functions in cell membrane interactions they can act as therapeutic agents (Zaragoza et al., 2009; Shao, 2011) or have an impact on the pathogenesis of causative agents of infections, such as those caused by pathogenic M. tuberculosis, Corynebacterium diphteriae, and the opportunistic pathogens, Mycobacterium avium, Mycobacterium intracellulare, Nocardia asteroides, Corynebacterium matruchotii, and Corynebacterium xerosis (Kuyukina and Ivshina, 2010). Trehalose lipids can be excreted into the cultivation supernatant or can be produced as non-covalently linked lipids bound to the cell wall or they can be cell wall integrated thus posing limits to quantities produced by the organisms, a disadvantage for its potential exploitation in large scale production processes.

\section{Non-Trehalose Glyolipids}

\section{Hexose-Comprising Glycolipids}

Besides the trehalose-containing biosurfactants and its congeners, several glycolipids have been elucidated that are produced by actinobacteria and share other hydrophilic moieties. By simply varying the carbon source in the growth media from n-alkanes to either sucrose or fructose, the hydrophilic part of the surfactant produced was reported to be switched from trehalose to fructose by members of the genus Arthrobacter, Corynebacterium, Nocardia, Brevibacterium, and Mycobacterium (Itoh and Suzuki, 1974) and sucrose in the case of the same genera except Mycobacterium (Suzuki et al., 1974). Compounds for which structures have been elucidated are listed in Table 4.

Besides the rhamnose-containing phenolic glycolipids mentioned in the oligosaccharide lipid section, the occurrence of other rhamnose-based lipids have recently been detected in a deep sea isolate identified as Dietzia maris (Wang et al., 2014) and has been identified as a $\mathrm{C} 10: \mathrm{C} 10$ di-rhamnolipid. This represents a unique occurrence within the class Actinobacteria. Other rhamnolipid producing actinobacteria are admittedly declared as producing strains in literature, however the surface active compounds produced have either not been elucidated or identified as rhamnolipids with debatable structural characterizations (Rhodoccocus fascians Gesheva et al., 2010, Renibacterium salonarium Christova et al., 2004, and a Nocardioides sp. VasilevaTonkova and Gesheva, 2005) (Table 11).

A different group of glycolipids are lipidic structures based on dimannose. Typically they are linked via a glycerol unit to different numbers of fatty acid chains. They have been reviewed in Shaw (1970) and structures have been identified for compounds produced by species belonging to the actinobacterial genera Micrococcus (Lennarz and Talamo, 1966), Curtobacterium (Mordarska et al., 1992), Saccharopolyspora (Gamian et al., 1996), Rothia (Pasciak et al., 2002, 2004), Nocardiopsis (Pasciak et al., 2004), Arthrobacter (Pasciak et al., 2010b) as well as the strain Sinomonas atrocyaneus (Niepel et al., 1997), formerly classified as Arthrobacter atrocyaneus. These dimannose based glycolipids are composed of hydrophilic $\alpha-\mathrm{D}$ mannopyranose dimers linked with two C14-C16 iso or anteiso fatty acid chains. One chain is directly esterified to the C6 hydroxyl group of one sugar unit, while the second fatty acid chain is linked via a glycerol moiety to the C3 of the same sugar unit. The glycerol moiety is monoacylated at either the primary or secondary methylene position (9, Table 4) and its acylation site can be used to distinguish taxonomic properties of the different producer strains. These compounds have been isolated intracellularly and they act as precursors and cell membrane anchors for the synthesis of lipoarabinomannan, a polymeric surfactant and actinobacterial cell wall component (Pakkiri and Waechter, 2005) (see section on polymeric biosurfactants).

The coexistence of galactosyl diglycerides (10, Table 4) in Arthrobacter scleromae and Arthrobacter globiformis (Pasciak et al., 2010b) have been described and can be used as a glycomarker to distinguish these strains from the opportunistic pathogens, Rothia mucilaginosa and Rothia dentocariosa (Pasciak et al., 2002, 2004).

\section{Macrocyclic Glycosides}

Among the biosurfactants produced by actinobacteria, macrocyclic glycosides (Table 5) and macrocylcic dilactones (Table 6) can be distinguished and are often known to exhibit bio-activity against a range of organisms. The aliphatic macrolide antibiotic, brasilinolide, is produced by Nocardia brasiliensis and exhibits both antifungal and antibacterial activity. Three different variants have been described by Tanaka et al. (1997), Mikami et al. (2000) and Komatsu et al. (2004). All consist of a C32-membered macrolide with a sugar moiety but differ with regards to the acylation site of a malonic acid ester side chain (11, Table 5). The C16-membered dimeric macrolide elaiophylin and its variants have been isolated from various Streptomyces spp. including high producer strains. It exhibits bio-active properties against intestinal worms as well as antimicrobial, antitumor and immunosuppressant activities. A putative $95 \mathrm{kbp}$ biosynthetic gene cluster of elaiophylin has been proposed (Haydock et al., 2004). Dembitsky $(2005 a, c)$ reviewed the different types of C14-membered lactam rings that are attached to an aminosugar (12, Table 5). Fluvirucin has been isolated from various Actinomadura spp., Streptomyces spp., Microtetraspora spp., and Saccharotrix mutabilis. The different fluvirucins share a common lactam ring unit but differ in terms of glycosylation. All of them act as potent antifungal 
TABLE 4 | Non-trehalose comprising glycolipids produced by actinobacteria.

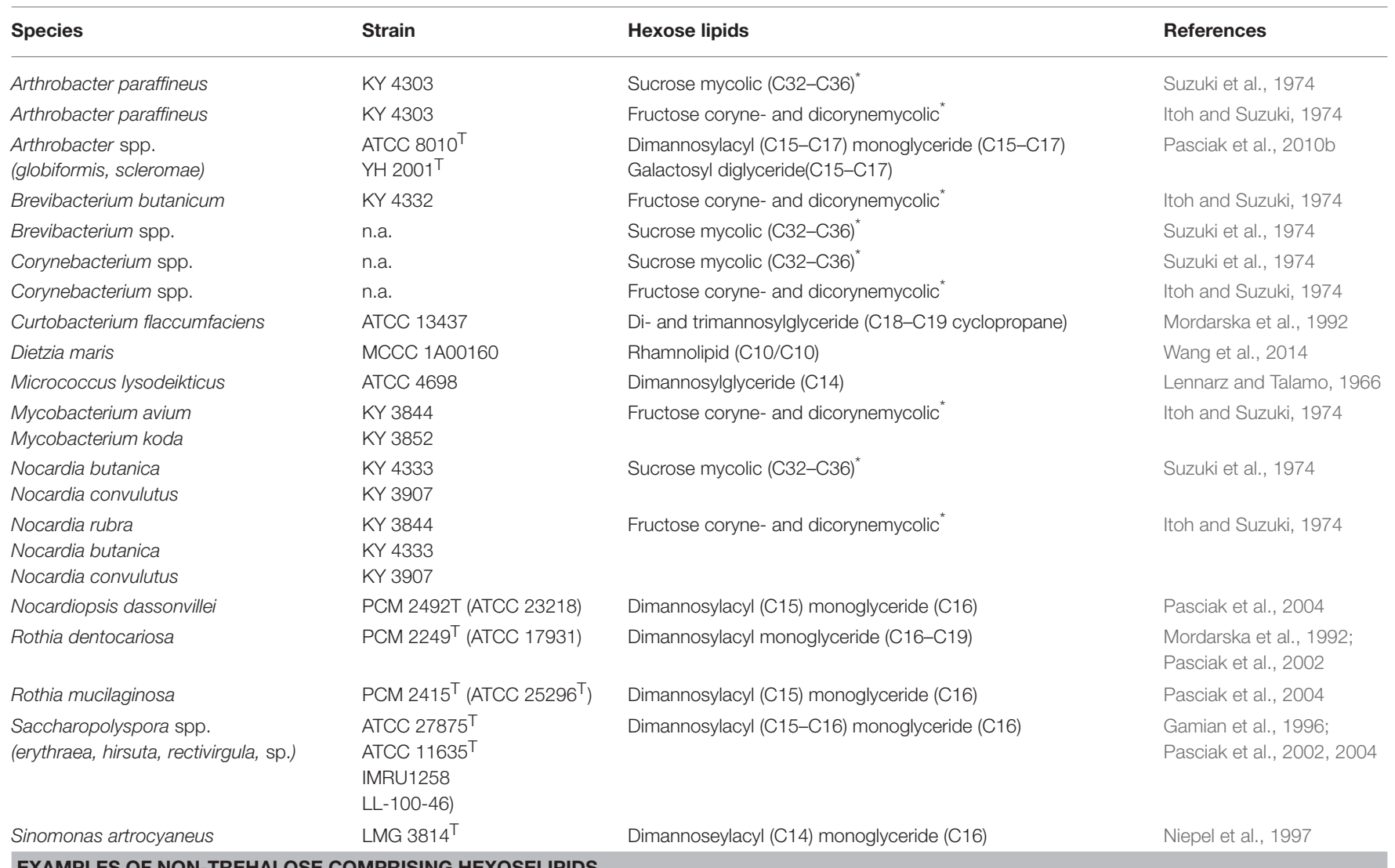

\section{EXAMPLES OF NON-TREHALOSE COMPRISING HEXOSELIPIDS}

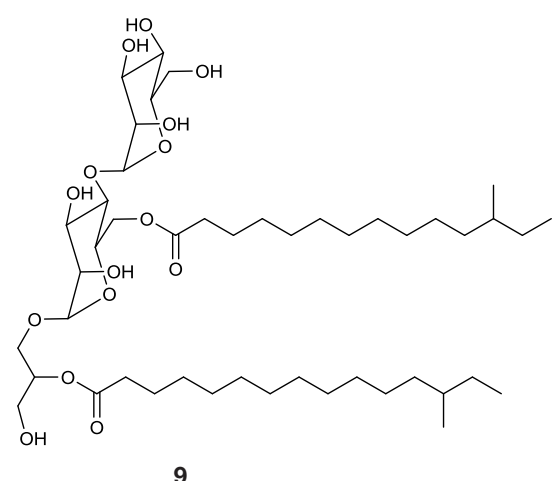

Dimannosylacyl monoglyceride produced by Rothia mucilaginosa

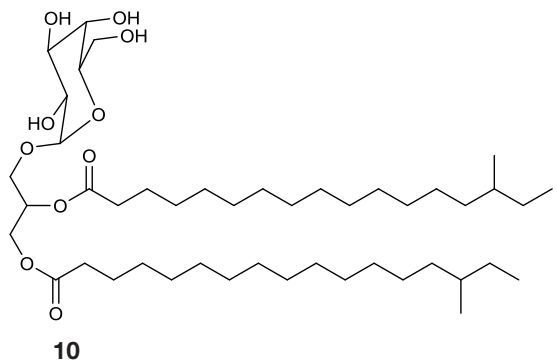

Galactosyl diglyceride produced by Arthorbacter globiformis and Arthrobacter scleromae

n.a., no information available; "Sucrose and fructose based surfactants are variants of trehalose lipids.

agents against Candida spp. and show antiviral properties against influenza A virus (Dembitsky, 2005c).

Among the macrocyclic dilactones, glucolypsin, an acylglucose dimer has been isolated from Streptomyces purpurogeniscleroticus and Nocardia vaccinii by Qian-Cutrone et al. (1999). This extraordinary glycolipid is formed out of two glucose units linked to identical iso-branched $\mathrm{C} 18$ acyl chains that each carry a methyl group at $\mathrm{C} 2$ and a hydroxyl group at $\mathrm{C} 3$ of the acyl chain. By connecting the $\mathrm{C}^{\prime}$ of the glucose molecule to the carboxy-C1 of the fatty acid chain, a rotationally symmetric dimer is formed (13,
Table 6). Glucolypsin variants with $\mathrm{C} 18$ and $\mathrm{C} 17$ fatty acid chains of the same type also occur. Glycolypsin is reported to increase the activity of glucokinases by relieving its inhibition via long chain fatty acyl CoA esters (Qian-Cutrone et al., 1999). Derivates of glucolypsin that share a common backbone, have been shown to exhibit antiviral and antibiotic properties. In contrast to glucolypsin, the acylglucose dimer of fattiviracins (C24/C26) and cycloviracins (C24/C33) are built up out of trihydroxy fatty acids, each of them glycosidic linked to a further glucose unit at the third hydroxyl group. Cycloviracins are characterized by 
TABLE 5 | Macrocyclic glycosides produced by actinobacteria.

\begin{tabular}{|c|c|c|c|}
\hline Species & Strain & Macrocyclic glycoside & References \\
\hline $\begin{array}{l}\text { Actinomadura spp. } \\
\text { (roseorufa roseorura, vulgaris, yumaensis) }\end{array}$ & Various & Fluvirucin (14C macrolide) & $\begin{array}{l}\text { Reviewed in: Dembitsky, } \\
\text { 2005a,c }\end{array}$ \\
\hline Microtetraspora pusilla & R359-5 & Fluvirucin B1 (14C macrolide) & Dembitsky, 2005a \\
\hline Microtetraspora tyrrheni & Q464-31 & Fluvirucins (14C macrolide) & Dembitsky, 2005a,c \\
\hline Nocardia brasiliensis & IFM 0406 & $\begin{array}{l}\text { Brasilinolide A, B, C } \\
\text { (32C macrolide) }\end{array}$ & $\begin{array}{l}\text { Tanaka et al., 1997; Mikami et al., } \\
\text { 2000; Komatsu et al., } 2004\end{array}$ \\
\hline Saccharothrix mutabilis & R869-9 & Fluvirucin A2 (14C macrolide) & Dembitsky, 2005a \\
\hline $\begin{array}{l}\text { Streptomyces spp.* } \\
\text { (antibioticus, erythreus, felleus, hygroscopicus, melanosporus, } \\
\text { narbonensis, spinichromogenes, violaceoniger) }\end{array}$ & various & $\begin{array}{l}\text { Elaiophylin and derivates } \\
\text { (16C macrolide) } \\
\text { Fluvirucin (14C macrolide) }\end{array}$ & Reviewed in: Dembitsky, 2005a \\
\hline
\end{tabular}

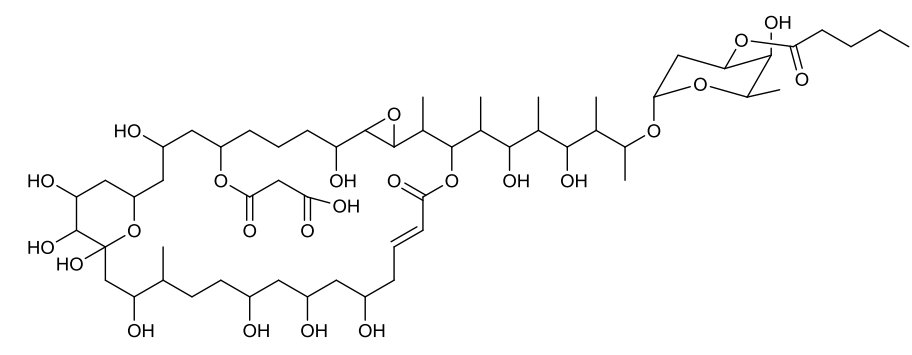

11

Brasilinoide A produced by Nocardia brasiliensis

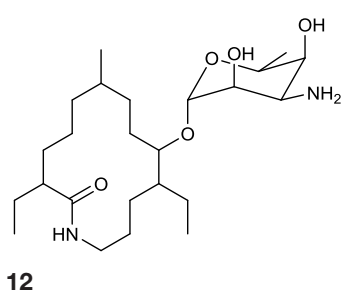

Fluvirucin B1 produced by Actinomadura vulgaris subsp. lanata

*Several producing strains are reported.

a fifth glucose unit bound to the C26 fatty acid chain, the three non-cyclic sugar units are methoxylated at C2, and the methyl branches at $\mathrm{C} 2$ of the fatty acid moieties are missing. Congeners of fattiviracin are divided into five families according to the length of their fatty acid moiety with each family showing similar antiviral activity against herpes, influenza and human immunodeficiency viruses (Uyeda, 2003). No alterations in the fatty acid chain length of cycloviracins have been reported. Fattiviracins (14, Table 6) have been shown to be produced by Streptomyces microflavus (Uyeda et al., 1998) and cycloviracins (15, Table 6) by Kibdelosporangium albatum (Tsunakawa et al., 1992b).

\section{Terpenoids and Terpene Glycosides}

Actinobacterial terpenoid and terpene glycosides are summarized in Table 7. Vancoresmycin is a C65 highly oxygenated terpenoid glycoside produced by an Amycolatopsis sp. It contains a tetramic acid unit and is glycosidic linked to a methylated carbohydrate moiety containing one amino group (16, Table 7). Antimicrobial effect against various bacteria was reported by Hopmann et al. (2002), most notably against species resistant to the antibiotic vancomycin (often considered to be the antibiotic of last resort for the treatment of resistant bacteria). Besides the terpenoid glycoside, several different types of terpene glycosides are produced by actinobacterial strains. They are surfactants that mostly carry terminal hydrophilic groups linked by a hydrophobic carotenoid moiety.

Terpene glycosides have been elucidated as products obtained from members of the following genera: Corynebacterium (Weeks and Andrewes, 1970), Arthrobacter (Arpin et al., 1972), Rhodococcus (Takaichi et al., 1997), and Micrococcus (Osawa et al., 2010) (Table 7). Most of them share a backbone of a C50 atom carotenoid. They can either be linked to one or two hydroxyl groups at the terminal ends (decaprenoxanthin and sarcinaxanthin) or one hydroxyl group and one glycosidic moiety (corynexanthin, decaprenoxanthin monoglycoside and sarcinaxanthin monoglycoside). Di-glycosylated forms are found within Arthrobacter and Micrococcus (decaprenoxanthin diglucoside and sarcinaxanthin diglucoside) (17, Table 7) and further exist as an acetylated form at all hydroxyl groups. The terpene glycosides produced by Rhodococcus rhodochrous, differ from the one mentioned above, as they contain a monocyclic carotenoid backbone linked to a glucopyranosyl residue at the non-cyclic end (18, Table 7). The glucose unit is further acylated at C6 to a C36-C50 mycolic acid moiety leading to carotenoid glucoside mycolic acid esters. These terpene glycosides are mainly found in pigmented bacteria and it is hypothesized that they act as antioxidants to protect organisms from injuries caused by free radicals (Osawa et al., 2010).

\section{Polymeric Biosurfactants}

The most common polymeric surfactants produced by actinobacteria are macro-amphiphilic lipoglycans such as lipoarabinomannan and its precursors, lipomannan and phosphatidylinositol mannosides. In contrast to the core of the actinobacterial cell wall, arabinogalactan and peptidoglycan, these polymeric lipoglycans are non-covalently attached to the cell membrane although phosphatidylinositol mannides are structurally related to lipomannan and lipoarabinomannan anchor units. These polymeric glycolipids have been isolated from Mycobacterium spp., Gordonia spp., Rhodococcus spp., 
TABLE 6 | Macrocyclic dilactones produced by actinobacteria.

\begin{tabular}{llll}
\hline Species & Strain & Macrocyclic dilactones & References \\
\hline Kibdelosporangium albatum & ATCC 55061 & Cycloviracin B1 and B2 (C23/C26) & Tsunakawa et al., 1992a,b \\
Nocardia vaccinii & WC65712 & Glucolypsin A and B (C19/C19) & Qian-Cutrone et al., 1999 \\
Streptomyces microflavus & No.2445 & Fattiviracin a1 (C22-28/C22-24) & Uyeda et al., 1998; Yokomizo et al., 1998 \\
Streptomyces purpurogeniscleroticus & WC71634 & Glucolypsin A and B (C19/C19) & Qian-Cutrone et al., 1999
\end{tabular}

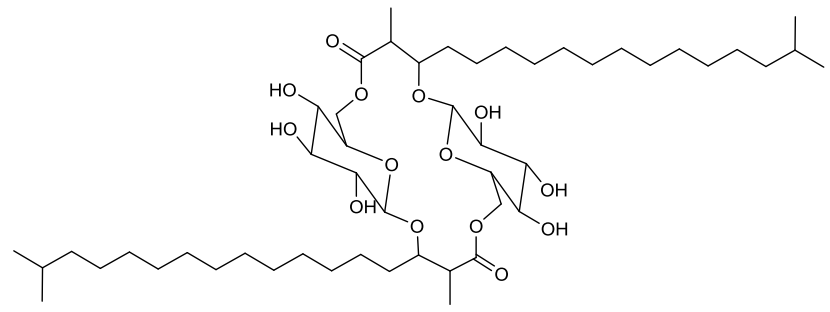

13

Glucolypsin A produced by Nocardia vaccinii and Streptomyces purpurogeniscleroticus

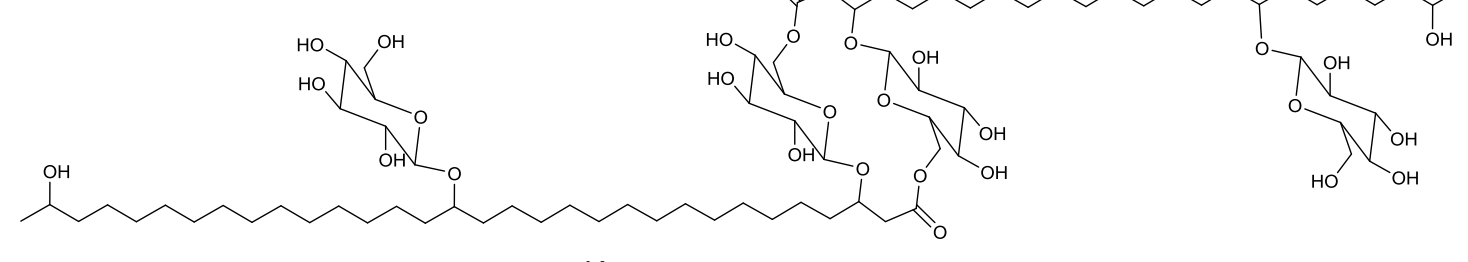

14

Fattiviracin produced by Streptomyces microflavus

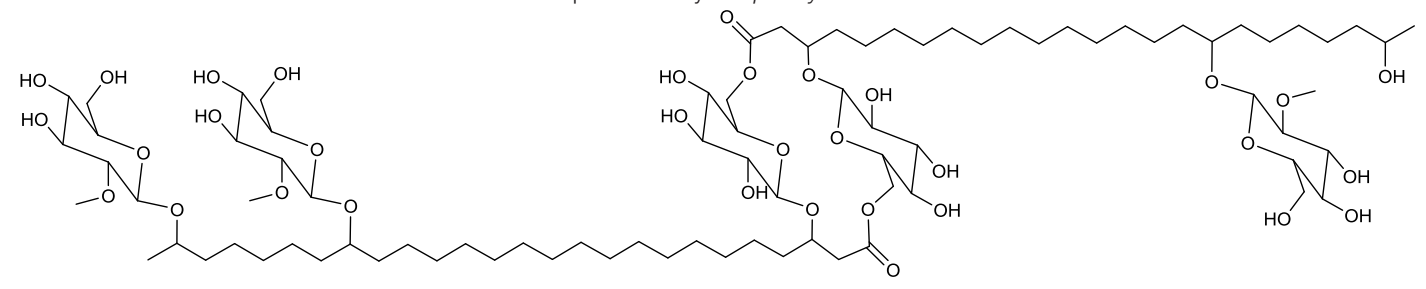

15

Cycloviracin $\mathrm{B}_{1}$ produced by Kibdelosporangium albatum

Dietzia maris, Tsukamurella paurometabolus, Turicella otitidis, and Amycolatopsis sulphurea (Table 8). Except for A. sulphurea, all of these strains belong to the suborder Corynebacteridae that are known to contain mycolic acids in their cell wall. It comprises the presence of mycolic acids and contain lipid rich cell envelope structures (Sutcliffe, 1997) forming an extremely robust and impermeable cell envelope (Berg et al., 2007). Lipoarabinomannans are well known to cause immunorepressive functions in diseases such as tuberculosis and leprosy that are caused by the pathogenic mycobacterial strains $M$. tuberculosis and M. leprae. However, non-pathogenic species have also been shown to produce lipoarabinomannans and are reported to have an opposite effect thus stimulating pro-inflammatory responses (Briken et al., 2004). The mannan core of lipoarabinomannan and the number of branching units is species dependent. Further differences in its structure is traced back to capping motifs present at the non-reducing termini of the arabinosyl side chains. Mannan caps are mainly present in pathogenic strains, whereas inositol phosphate caps are present in non-pathogenic mycobacteria
(Briken et al., 2004). Lipoarabinomannans show structural similarity to its precursors lipomannan and phosphatidylinositol mannoside and consist of an $\alpha-1,6$ linked mannan core with frequent $\alpha-1,2$ mannose branches leading to a mannan backbone of approximately 20-25 mannose residues substituted with arabinofuran residues that carry terminal extension motifs, which vary among the producer species (Berg et al., 2007). The lipophilic part consists mainly of $\mathrm{C} 16$ glycerides that are linked to the mannan core by a phosphate group (19, Table 8$)$.

\section{Lipopeptides}

Cyclic and linear lipopeptides are produced by various actinobacterial strains and are summarized in Table 9.

\section{Cyclic Lipopeptides}

Cyclic lipopeptides are the most common type of lipopeptides and consist of a peptide chain of various types and numbers of amino acids circularized and linked to mainly one fatty acid 
TABLE 7 | Terpenoid and terpene-containing biosurfactants produced by actinobacteria.

\begin{tabular}{llll}
\hline Species & Strain & Terpenoids and terpenes & References \\
\hline Amycolatopsis sp. & DSM 12216 & Vancoresmycin (65C terpenoid) & Hopmann et al., 2002 \\
Arthrobacter sp. & M3 & Corynexanthin mono- and diglycosides (C50 terpene) & Arpin et al., 1972; Dembitsky, 2005b \\
Corynebacterium sp. & CMB 8 & Corynexanthin (C50 terpene) & Weeks and Andrewes, 1970 \\
Micrococcus yunnanensis & AOY-1 & Sarcinaxanthin, sarcinaxanthin mono- and diglucosides (C50 terpene) & Osawa et al., 2010 \\
Rhodococcus rhodochrous & RNMS1 & Carotenoid (C40 terpene) glycoside (C36-C50 mycolic) & Takaichi et al., 1997
\end{tabular}

\section{EXAMPLES OF TERPENE AND TERPENOID GLYCOSIDES}<smiles>CC(=CCC(O)CC(O)CCC(C)C(O)C(C)C(O)CCCC(O)C(C)C(O)C(C)=CC(C)C(=O)C(C)=CC(O)C(O)CC(O)CC(OC1OC(C)C(O)C(N)C1O)C(C)CCC(O)CC(O)CCC(C)C(O)C(C)C(O)C(C)C)C(=O)C1=C(O)C(=CC(C)C)N(C)C1=O</smiles>

16

The terpenoidic glycoside vancoresmycin produced by Amycolatopsis sp.

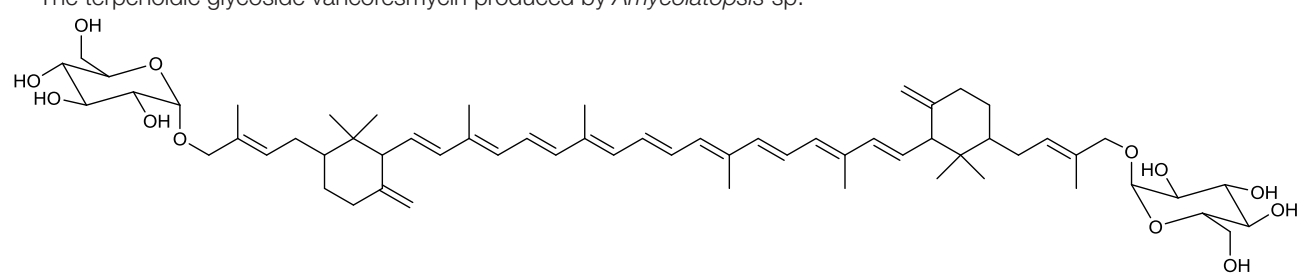

17

Sarcinaxanthin diglycoside produced by Micrococcus yunnanensis

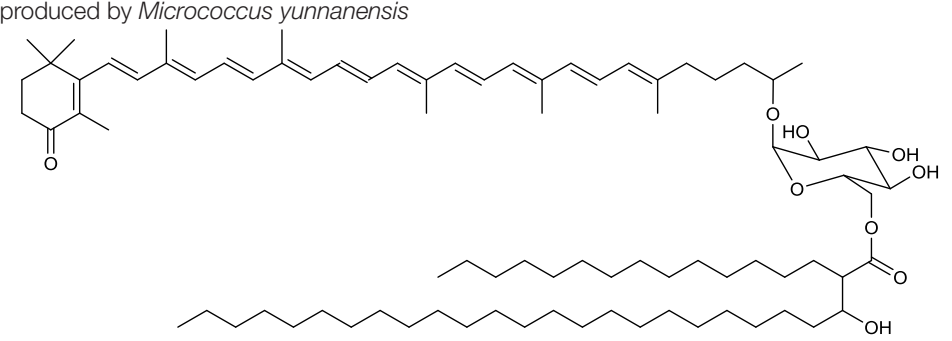

18

Carotenoid glycoside esterified with a rhodococcus type mycolic acid produced by Rhodococcus rhodochrous

chain. A surfactant often falsely cited to be produced by an actinobacterium but not of actinobacterial nature, is the eleven amino acid cyclic lipopeptide arthrofactin. It was initially postulated to be produced by an Arthrobacter sp. (Morikawa et al., 1993) but later corrected to originate from a Pseudomonas strain (Roongsawang et al., 2003).

Cyclic lipopeptides that have been reported within the class Actinobacteria are the six amino acid containing cystargamide produced by Kitasatospora cystarginea (Gill et al., 2014) (20, Table 9), the thirteen amino acid containing daptomycin produced by Streptomyces roseosporus (Debono et al., 1987) (21, Table 9) and the depsipeptide ramoplanin, containing 16 amino acids, and which is produced by an Actinoplanes sp. (Ciabatti et al., 1989) (22, Table 9). All of them are cyclic due to an ester linkage between the carboxyl terminus and a hydroxyl group of either a threonine or hydroxyl-asparagine.

In cystargamide, the smallest cyclic lipopeptide, an uncommon 2,3 epoxy fatty acid chain (C10) is linked to the threonine amine. Besides proteinogenic amino acids, cystargamide further contains rare $5^{\prime}$-hydroxy-trypthophan and $4^{\prime}$-hydroxyphenylglycine (20, Table 9). No antimicrobial activity of cystargamide could be demonstrated (Gill et al., 2014).

An outstanding example of successful screening for a surfactant with bioactive properties are A21978C complexes, known as precursors of daptomycin. They were structurally elucidated in 1987 (Debono et al., 1987) and A21978C comprises thirteen different amino acids, 10 of them in the cyclic part of the structure and three in the extension of the hydrophobic tail (21, Table 9). Three different lipophilic tails are known, C10 anteiso, C11 iso branched and C12 anteiso. The most bioactive form of A21978C is daptomycin and has been generated by enzymatic deacylation of the mixture of lipophilic tails and chemical reacylation with a decanoyl fatty acid moiety. It was approved by the U.S. Food and Drug Association (FDA) in 2003 as the first antibiotic of its kind, and commercialized as cubicin ${ }^{\circledR}$. It is active against various gram positive bacteria including the methicilin-resistant pathogen Staphylococcus aureus, penicillin-resistant Streptococcus pneumoniae and vancomycin resistant enterococci (Miao 
TABLE 8 | Polymeric glycolipids of actinobacterial origin.

\begin{tabular}{|c|c|c|c|}
\hline Species & Strain & Polymeric glycolipid & References \\
\hline Corynebacterium matruchotii & NCTC 10207 & Lipoarabinomannan & Sutcliffe, 1995 \\
\hline Turicella otitidis & DSM 8821 & Lipoarabinomannan & Gilleron et al., 2005 \\
\hline $\begin{array}{l}\text { Mycobacterium spp." } \\
\text { (avium, bovis, chelonae, fortuitum, kansaii, } \\
\text { leprae, smegmatis, tuberculosis, etc.) }\end{array}$ & Various & Lipoarabinomannan and lipomannan & $\begin{array}{l}\text { Reviewed in: Chatterjee and Khoo, } \\
\text { 1998; Brennan, 2003; Nigou et al., } \\
\text { 2003; Briken et al., } 2004\end{array}$ \\
\hline $\begin{array}{l}\text { Rhodococcus spp." } \\
\text { (equi, rhodnii, ruber, etc) }\end{array}$ & Various & Lipoarabinomannan & Reviewed in: Sutcliffe, 1997 \\
\hline Tsukamurella paurometabola & DSM 20162 & Lipoarabinomannan & Gibson et al., 2004 \\
\hline Amycolatopsis sulphurea & DSM 46092 & Lipoarabinomannan & Gibson et al., 2003 \\
\hline
\end{tabular}

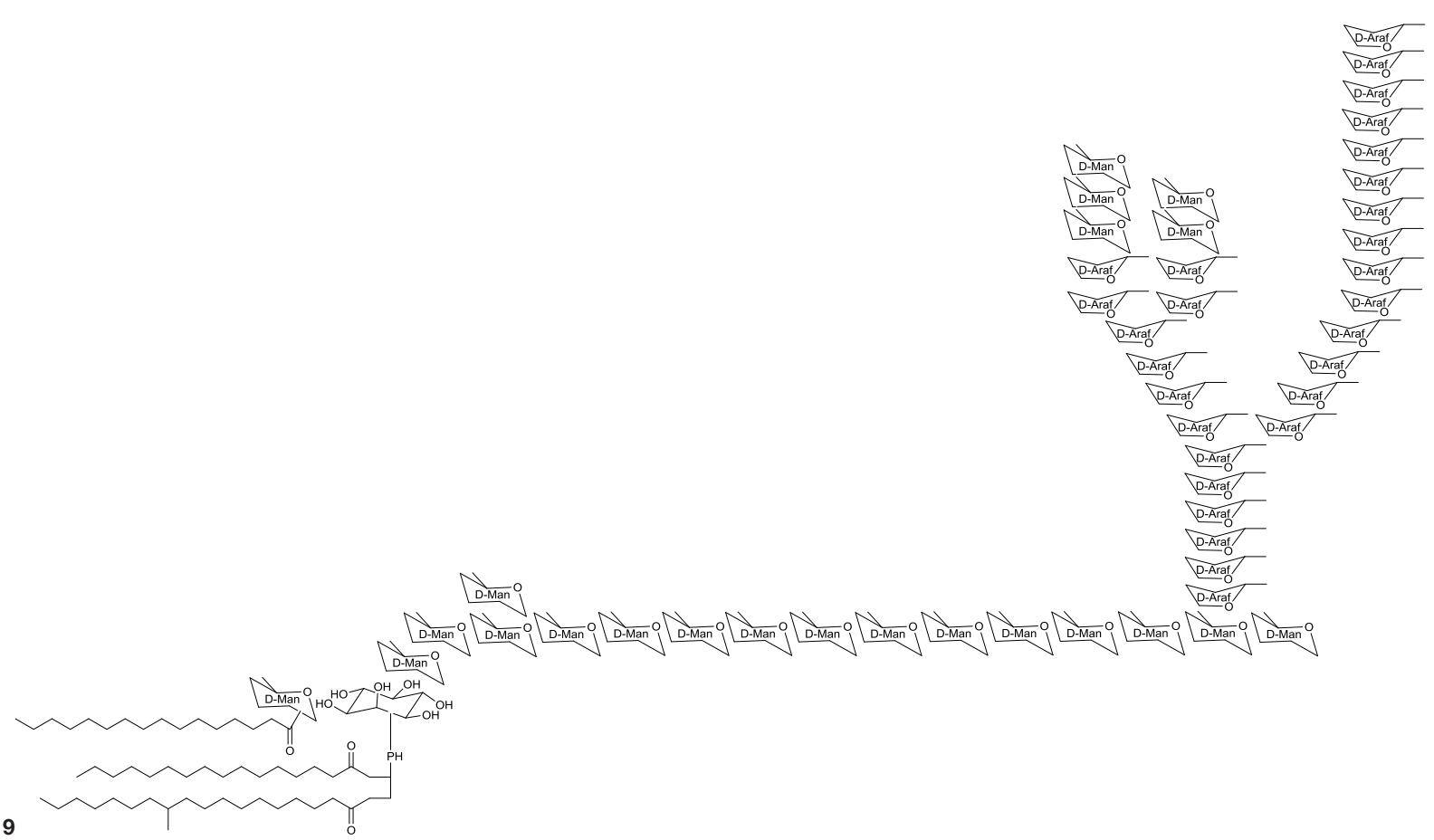

Simplified structure of lipoarabinomannan produced by Mycobacterium tuberculosis with only one arabinofuran branch shown. Modified from Berg et al. (2007)

*Several producing strains are reported.

et al., 2005). Its ability to act as an antimicrobial requires the presence of calcium. The cyclic lipopeptide oligomerizes and uses its C10 hydrophobic tail to interact with the bacterial membrane creating a membrane perforation and cell death. This displays a novel mode of action among antimicrobial agents. Daptomycin shows high activity and a resistance to its mechanism is more difficult to generate compared to conventional antibiotics (Vilhena and Bettencourt, 2012). It is produced by a non-ribosomal peptide synthetase (NRPS) in S. roseosporus. The NRPS contains three subunits whose main genes have recently been identified in a $128 \mathrm{~kb}$ cluster as $d p t \mathrm{~A}, d p t \mathrm{BC}$, and $d p t \mathrm{D}$ (Miao et al., 2005) with several other genes necessary to synthesize an active form of daptomycin. Its production yield of approximately $0.5 \mathrm{~g} \mathrm{l}^{-1}$, is relatively low compared to industrial production of other microbial products. Current attempts for a heterologous production not only target novel congeners of daptomycin but also the search for high producing strains. Similar production yields compared to the wild type strain have been reported for heterologous production which was developed using a combination of metabolic flux analysis and genetic modifications (Huang et al., 2012).

Antimicrobial activity against gram positive bacteria has also been detected for ramoplanin produced by an Actinoplanes sp. It contains 17 amino acids, 16 of which are part of the cyclic section of the compound. It is further glycosylated at a hydroxyphenylglycine with either di-mannose (Ciabatti et al., 1989) or mannose (Gastaldo et al., 1992), thus its classification as a glycolipopeptide. Besides its glycosylation pattern, members of ramoplanin can be differentiated by their acyl amides that consist of different di-unsaturated fatty acids linked to the distal hydroxyl-asparagine. The fatty acid chain varies in 
TABLE 9 | Lipopeptides produced by actinobacterial strains.

\begin{tabular}{|c|c|c|c|}
\hline Species & Strain & Lipopeptide & References \\
\hline Rhodococcus sp. & MCCC 1A00197 & rhodocfactin & Peng et al., 2008 \\
\hline Streptomyces roseosporus & NRRL 11379 & A21978C (daptomycin) (13aa, C10-12) & Debono et al., 1987 \\
\hline Streptomyces tendae & Tü 901/8c & Streptofactin & Richter et al., 1998 \\
\hline
\end{tabular}<smiles>CCCCCCCC1OC1C(=O)NC(C(=O)NC(Cc1ccccc1)C(=O)N[C@@H](CCC(=O)O)C(=O)N[C@@H](Cc1c[nH]c2ccc(O)cc12)C(=O)N[C@@H](C(=O)NCC(=O)O)c1ccc(O)cc1)C(C)OC1CO1</smiles>

20

Cystargamide produced by Kitasatospora cystarginea

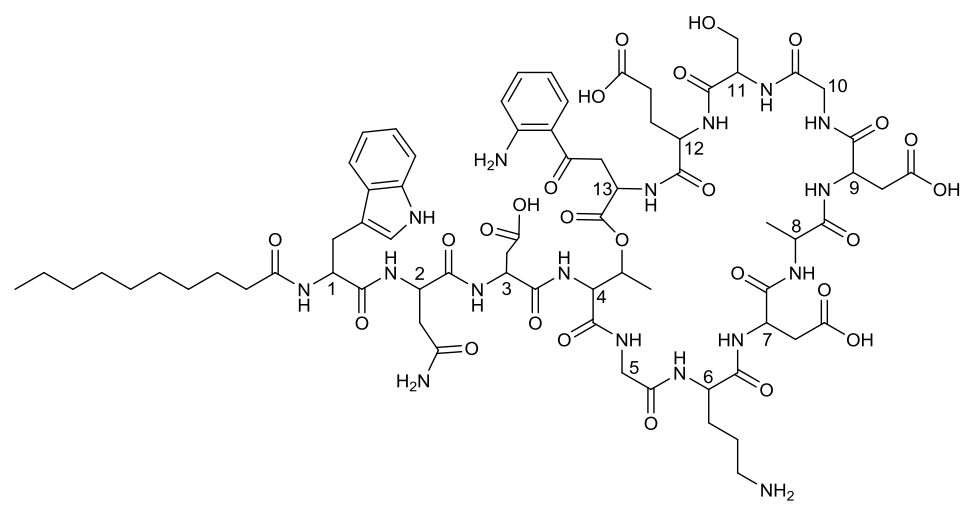

21

Daptomycin reacylated with decanoic acid from the core complex A21978C, produced by Streptomyces roseasporus

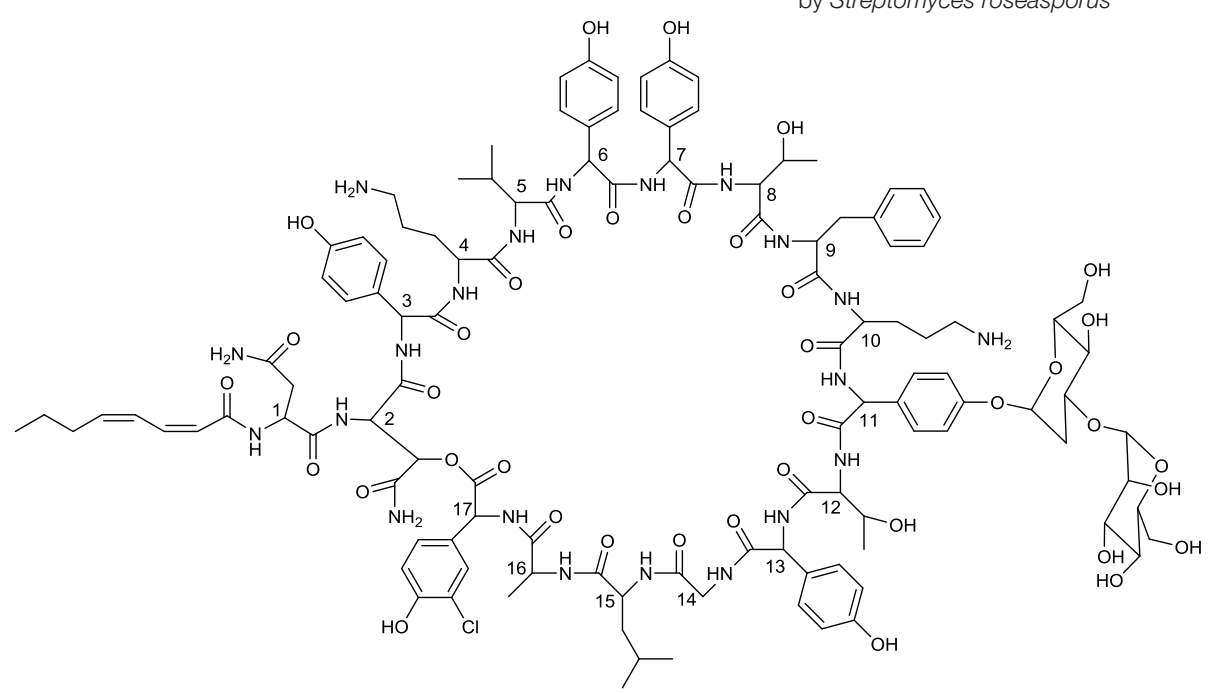

22

Dimannosylated ramoplanin produced by Actinoplanes sp.

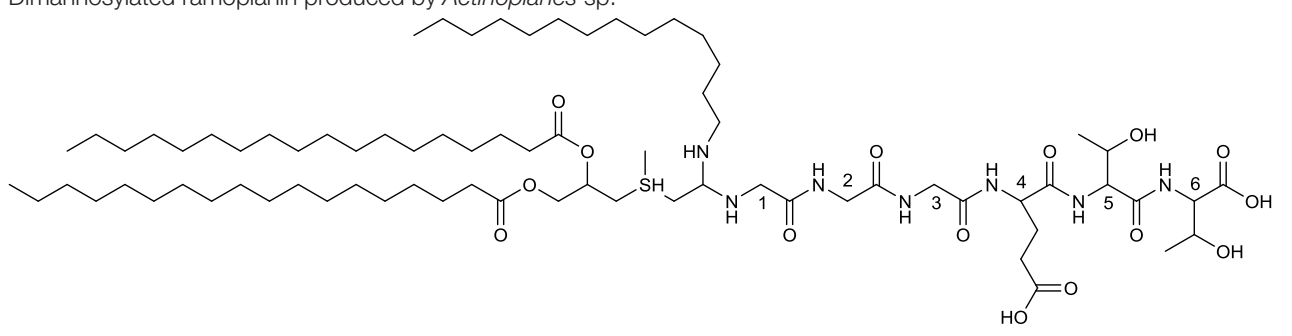

23

Linear TAN-1511 A produced by Streptosporangium amethystogenes subsp. fukuiense

aa, amino acid. 
length between C8 and terminal branched C9 and C10 (22, Table 9).

A peptide-based surfactant produced by Streptomyces tendae, streptofactin, was found to contain hydrophobic amino acids, but lacked fatty acid chains (Richter et al., 1998).

\section{Linear Lipopeptides}

Linear lipopeptides have been found in Streptosporangium amethystogenes (Takizawa et al., 1995). They are reported to protect against infections in patients with leucopenia caused by cancer therapies by stimulating bone marrow cells. Different structures of these compounds are described, all share a $4^{\prime}$-thio C7 fatty acid chain with two ester linked C16-C19 fatty acid chains and one amide linked C13-C15 fatty acid chain. Three glycine amino acids are linked at the amide bond of the thio fatty acid with three to four proceeding amino acids varying in type (23, Table 9).

\section{Other Actinobacterial Biosurfactants}

\section{Phenazine Ester}

Phenazines are a rare class of alkaloid esters. A marine Streptomyces sp. has been described to produce a phenazine ester that contain the desoxy pyranose quinovose esterified at either C3 or C4 to the carboxyl end of the phenazine. This phenazine-quinovose ester has been shown to exhibit antimicrobial activity. Several different types of the compound have been characterized also varying in hydroxylation and acetylation pattern at the desoxyglucose unit (Pathirana et al., 1992) (24, Table 10).

\section{Amide Glycosides}

Various surfactants with nucleoside fatty amide glycoside structure are produced by actinobacteria. A group of amide glucosides is based on the uracil and disaccharide-containing tunicamycin, a glycoprotein with antibacterial properties (Dembitsky, 2005c). In this glycoprotein, two saturated or unsaturated partly branched fatty acid chains varying in length are linked via an amide to the galactosamine/glucosamine disaccharide. Besides tunicamycin, produced by Streptomyces spp., the tunicamycinbased surfactants streptovirudin (containing dihydrouracil) and corynetoxin (25, Table $\mathbf{1 0})$ have been reported. The latter is produced by Corynebacterium rathayi, a pathogen of rye grass. The organism multiplies within the galls of sheep spreading the toxic metabolite (Frahn et al., 1984). In addition, the inhibitors of bacterial peptidoglycan synthesis, liposidomycin A, B, and C, have been reported to be produced by Streptomyces griseosporus. Liposidomycin A contains the so far uniquely described fatty acid composition of $3^{\prime}$-hydroxy-7,10-hexadecanoic acid (Dembitsky, 2005c) (26, Table 10).

\section{Not Yet Elucidated Surfactants and their Producing Strains}

Surface or emulsifying activity has been observed to occur from secondary metabolites of other members of the class
Actinobacteria. Table 11 gives an overview of strains that are described to produce surface active compounds. Only some of the structures of these compounds have been partially elucidated.

Partly characterized surface active flocculants consisting of lipids, fatty acids and corynemycolic fatty acids of Corynebacterium lepus have been described by Cooper et al. (1979b). In addition, eleven different glycolipids that consist of hexoses and pentoses linked to diverse fatty acid moieties that vary in length of C10-C18 have also been described.

Besides D. maris (see glycolipid section), three other putative rhamnolipid-producing actinobacteria have been described. Vasileva-Tonkova and Gesheva (2005) and Gesheva et al. (2010) detected thin layer retention values equal to L-rhamnose after acid hydrolysis of a biosurfactant produced by a Nocardioides $\mathrm{sp}$. and Rhodococcus fascians. The putative rhamnolipid was not further examined in terms of the hydrophilic moiety or fatty acid compositions. Christova et al. (2004) reported the production of rhamnolipid by Renibacterium solmonarium in comparison to commercial rhamnolipids in thin layer chromatography and infrared spectroscopy. The infrared spectra showed homologies to ester and carboxylic groups; thin layer chromatographic data were not shown in the study. In all cases the detection of rhamnolipids were putative and further structural analyses remains necessary for confirmation.

Other surface active compounds were only putatively classified based on the component analysis of the crude extract toward lipid, peptide and carbohydrate compositions. Based on this limited information, it was concluded that the production of either glycolipids or lipopeptides took place (Table 11).

Mass spectroscopic analysis greatly assisted to partly characterize the putative wax esters produced by D. maris (Nakano et al., 2011). In addition, Kiran et al. (2010a,b, 2014) described the production of furan-containing glycolipids in Brachybacterium spp., Brevibacterium spp., and Nocardiopsis spp. By analyzing hydrophilic and hydrophobic moieties after acid hydrolization, database comparison of gas chromatography-mass spectroscopic plots were used. ${ }^{1} \mathrm{H}$ NMR evaluation of compounds from the two latter strains were described to approve the resulting structure, however relative data were not shown.

Similar results have been observed for surface active extracts with a majority of peptidic compounds in the hydrophilic part in Brevibacterium aurum (Kiran et al., 2010c) where fractions of the biosurfactant showed molecular weights of C9-C29 methyl esters and a mass that putatively confers to a proline-leucine-glycine-glycine amino acid chain. However, mass spectroscopic database comparisons remains putative. Leucobacter komagate is described to produce surfactin or a surfactin-like lipopeptide. This was concluded from mass spectroscopy, ${ }^{1} \mathrm{H}$ NMR and infrared spectral data by Saimmai et al. (2012b), but the full elucidation of the structures could not be achieved.

The long list of non-elucidated actinobacterial surface active compounds underlines the extraordinary potential of finding novel biosurfactants in actinobacteria and displays the great need for structure elucidation to allow for a better understanding of the novelty and biodiversity of the compounds produced. 
TABLE 10 | Other biosurfactants produced by actinobacteria.

\begin{tabular}{|c|c|c|c|}
\hline Species & Strain & Compound & References \\
\hline Streptomyces sp. & CNB-253 & Phenazine-quinovose & Pathirana et al., 1992 \\
\hline $\begin{array}{l}\text { Streptomyces spp.* } \\
\text { (griseoflavus, griseosporus, halstedii, } \\
\text { lysosuperficus, nursei, vinausdrappus) }\end{array}$ & various & $\begin{array}{l}\text { Fatty acid amide glycoside } \\
\text { (Tunicamycin, Streptovirudin, Liposidomycins) }\end{array}$ & Reviewed in: Dembitsky, 2005c \\
\hline Corynebacterium rathayi & n.a. & Corynetoxin & Frahn et al., 1984 \\
\hline
\end{tabular}

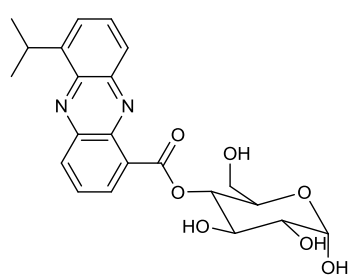

24<smiles>CCCCCCCCCCCC(CC(=O)OC1CN(C)C(C(COC2OC(CN)C(O)C2OS(=O)(=O)O)n2ccc(=O)[nH]c2=O)C(=O)N(C)C1C(=O)O)OC(=O)CC(C)CC(=O)O</smiles>

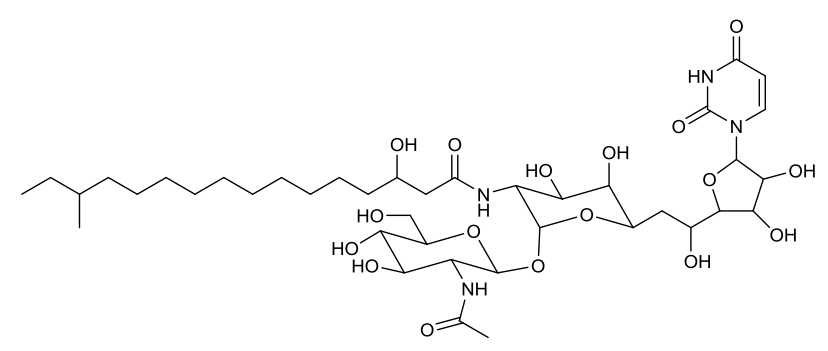

25

Corynetoxin produced by Corynebacterium rathayi

26

Liposidomycin A produced by Streptomyces sp.

*Several producing strains are reported.

\section{Structural Elucidations of Actinobacterial Surfactants}

Various factors have been shown to influence the production, extraction, purification and structure elucidation of novel biosurfactants produced by actinobacterial strains. Due to their phenotypic growth characteristics, distinct membrane compositions and their function within the utilization of hydrocarbons, the surfactants produced are often membrane integrated, membrane associated, extracellular or a mixture of the above, and is always dependent on their particular function within the producing strains. Commonly the compounds produced exhibit antimicrobial properties, on the one hand proposing wide ranging applications, on the other resulting in opposing challenges during the production process. Special considerations are necessary when aiming for the extraction of the compound in an adequate amount and purity for structural elucidation as well as surfactant characterization. This section gives an overview of the most common techniques used to achieve successful structural elucidations.

\section{Detection}

Novel surfactant producing strains can be detected through the use of screening assays that determine a surfactant's activity either from liquid culture (cell-free supernatant or culture broth) or from solid agar plates. Various detection methods have been described, but they mostly focus on changes observed in surface tension or the solubilization and emulsification of hydrocarbons. High throughput compatible assays can be distinct from more precise assays that need several milliliters of the compound to be tested. The latter often are also applied to characterize the activity of a purified biosurfactant. Good reviews on screening techniques have been summarized by Walter et al. (2010) and Satpute et al. (2010).

\section{Production}

The manufacturing capacity of biosurfactants by a bacterial culture is limited. Wild type producing strains of the best described microbial surfactants, cultured with optimized process methods in suitable media and culture vessels reach production quantities of up to $422 \mathrm{~g} \mathrm{l}^{-1}$ for sophorose lipids (Daniel et al., 1998), $112 \mathrm{~g} \mathrm{l}^{-1}$ for rhamnose lipids (Giani et al., 1996), $110 \mathrm{~g} \mathrm{l}^{-1}$ for spiculisporic acids (Tabuchi et al., 1977), $106 \mathrm{~g} \mathrm{l}^{-1}$ for mannosylerythritol lipids (Morita et al., 2008) and 3,6 $\mathrm{g} \mathrm{l}^{-1}$ for surfactin (Yeh et al., 2005). These are rare exceptions within the typical amounts produced by microorganisms, which usually do not exceed milligram amounts. The production level is strongly influenced by non-favorable growth and production conditions due to a lack 
TABLE 11 | Actinobacterial strains identified to produce surface active compounds for which no structures have been elucidated.

\begin{tabular}{|c|c|c|c|}
\hline Species & Strain & Compound & References \\
\hline Actinopolyspora sp. & A18 & n.d. GLP & Doshi et al., 2010 \\
\hline Amycolatopsis tucumanensis & DSM 45259 & n.d. (bioemulsifier) & Colin et al., 2013 \\
\hline Brachybacterium paraconglomeratum & MSA21 & n.d. GL (putative furan lipid/C12) & Kiran et al., 2014 \\
\hline Brevibacterium aureum & MSA13 & n.d. LP (putative brevifactin/C18) & Kiran et al., 2010c \\
\hline Brevibacterium casei & MSA19 & n.d. GL (putative furan lipid/C18) & Kiran et al., 2010a \\
\hline Corynebacterium hydrocarboclastus & n.a. & n.d. polymer & Zajic et al., 1997 \\
\hline Corynebacterium lepus & n.a. & n.d. LP & Cooper et al., 1979a \\
\hline Corynebacterium lepus & n.a. & n.d. GL & Cooper et al., 1979a \\
\hline Corynebacterium lepus & n.a. & p.d. (lipid, fatty acid, mycolic acid) & Cooper et al., 1979b \\
\hline Corynebacterium xerosis & n.a. & n.d. LP & Margaritis et al., 1979 \\
\hline Dietzia maris & WR-3 & p.d. (putative wax-ester) & Nakano et al., 2011 \\
\hline Dietzia sp. & S-JS-1 & n.d. LP & Liu et al., 2009 \\
\hline Frankia sp. & Cpl1 & n.d. GL & Tunlid et al., 1989 \\
\hline Gordonia amarae & SC1 & n.d. (extracellular with high molecular weight) & Iwahori et al., 2001 \\
\hline Gordonia rubripertincta & DSM 46038 & n.d. & Pizzul et al., 2006 \\
\hline Gordonia sp. & ADP & n.d. & Pizzul et al., 2006 \\
\hline Gordonia sp. & BS29 & n.d. GL & Franzetti et al., 2010 \\
\hline Gordonia sp. & JE-1058 & n.d. (extracellular) & Saeki et al., 2009 \\
\hline Kocuria marina & BS-15 & n.d. LP & Sarafin et al., 2014 \\
\hline Leucobacter komagatae & 183 & p.d. LP & Saimmai et al., 2012b \\
\hline Microlunatus sp. & NA2 & n.d. & Saimmai et al., 2012a \\
\hline Nocardia erythropolis & ATCC 4277 & n.d. GL, PL & Macdonald et al., 1981 \\
\hline Nocardioides sp. & A-8 & n.d. GL (putative Rhamnolipid) & Vasileva-Tonkova and Gesheva, 2005 \\
\hline Nocardiopsis alba & MSA10 & n.d. LP & Gandhimathi et al., 2009 \\
\hline Nocardiopsis lucentensis & MSA04 & n.d. GL (putative furan lipid/C9) & Kiran et al., 2010b \\
\hline Oerskovia xanthineolytica & CIP 104849 & p.d. GL (hexose, pentose C10-C18) & Arino et al., 1998 \\
\hline Pseudonocardia sp. & BSNC30C & n.d. & Ruggeri et al., 2009 \\
\hline Renibacterium salmoninarum & 27BN & n.d. GL (putative Rhamnolipid) & Christova et al., 2004 \\
\hline Rhodococcus fascians & A-3 & n.d. GL (putative Rhamnolipid) & Gesheva et al., 2010 \\
\hline Streptomyces sp. & n.a. & n.d. GL & Khopade et al., 2011 \\
\hline
\end{tabular}

GL, Glycolipid; GLP, Glycolipiopeptide; LP, Lipopeptide; PL, Phospholipid; n.a., information not available; n.d., not determined; p.d., partly determined.

of knowledge about the organism used and compound produced when initially screening for novel surfactants or novel producer strains.

With a few exceptions (Qian-Cutrone et al., 1999; Kügler et al., 2014), the average minimum volume for successful structure elucidation of an actinobacterial biosurfactant, is typically 201 . Harvesting of the surfactants is type dependent and either whole cell broth (intracellular or membrane associated surfactants) or cell free supernatant is used as a starting point.

\section{Glycolipids}

A typical method for the extraction of surfactants from culture broth or supernatant is the use of two phase extractions. In a first step, if appropriate, non-polar solvents (e.g., n-hexane) are used to remove residual hydrocarbons from the cultivation broth. If extraction is carried out from whole cell broth or wet cell mass, glycolipids are either captured by direct cell extraction or by cell treatment (e.g., sonication) prior to the extraction.
In a second step, the surfactant is removed by repeated agitation with a medium polar solvent or solvent mixture. Most commonly, combinations of chloroform and methanol or polar aprotic solvents such as ethyl acetate or methyl-tert-butyl ether are used. A frequency solvent distribution for the extraction of glycolipids from "rare" actinobacteria is shown in Figure 2, comprising data of 47 two-phase extraction methods used to enrich surfactants produced from either cell-free supernatant or the culture broth. Depending on the chemical characteristics of the glycolipid, an acidification step ( $\mathrm{pH} 2-\mathrm{pH} 3)$ with subsequent incubation $\left(4^{\circ} \mathrm{C}\right)$ prior to the extraction process could result in enhanced product recoveries (Passeri et al., 1990; Konishi et al., 2014). Often, after dehumification, further washing steps are applied, either of a hydrophilic (e.g., ultrapure water) or a hydrophobic (e.g., n-hexane) nature. For the polymeric glycolipid lipoarabinomannan and related structures, a hot-phenol water method is almost exclusively used (Sutcliffe, 2000).

The glycolipids produced, mainly present in mixtures of different forms, need to be separated for structural analysis. 


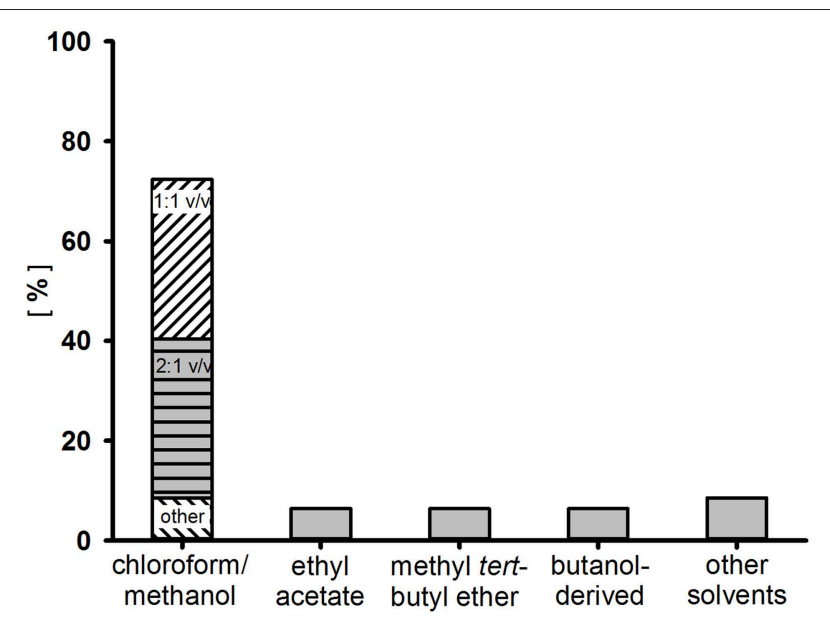

FIGURE 2 | Frequency distribution of solvents used for the enrichment of surfactants by two-phase extraction from the culture broth or cell free supernatant of $\mathbf{4 7}$ "rare" actinobacteria.
This procedure is usually performed by combinations of chromatographic steps using either gradient columns or preparative medium- and high pressure chromatography. In addition, preparative planar chromatographies are reported as an additional purification step for the isolation of pure compounds (Powalla et al., 1989; Pasciak et al., 2002, 2004). Rarely applied is the use of absorbers within the cultivation process. The number one choice for chromatography is the use of hydrophobicity affiliated separations with silicic acids as an absorbing material. In approximately $80 \%$ of structure reports from "rare" actinobacteria, silicic acid is used with various elution gradients of nonpolar and polar solvents. Separated compounds are often further purified by repetitive silica chromatography using different gradients or by subsequent (or preceding) steps with different column material. Therefore, either reverse-phase C18 chromatography or cellulose-based ionic interaction chromatography are widely used.

\section{Lipopeptides}

The diversity of different peptide-based surface active compounds produced by actinobacterial strains is much smaller than that of reported glycolipids. Depending on the lipopeptide produced, two different approaches for the concentration of the surfactants are used. Either the lipopeptide can be precipitated from the liquid culture/supernatant by either using cold acetone, methanol, salt concentrations, acidic environments, or a direct extraction by medium polar solvents similar to those used for glycolipids have been reported. Besides the chromatographic purification steps used for glycolipids, gel filtration has been successfully used as an additional step (Takizawa et al., 1995).

\section{Structural Elucidation}

Once a compound is purified to a sufficient extent, component analysis, specific staining methods and mass spectroscopic examinations are widely used to get a first hint about the type of surfactant produced. A more detailed schematic of the surfactant can be deduced from mass spectroscopy fragmentation studies, often revealing mass abundances of separated hydrophilic and hydrophobic parts of the glycolipid. However, complete structure examinations (of complete compounds or hydrolyzed components) rely on multi-dimensional nuclear magnetic resonance spectroscopy.

\section{Natural Habitats of Biosurfactant-Producing Actinobacteria}

With the exception of a few strains, the great majority of surfactant-producing actinobacteria have been isolated from three different environments. These are: (1) Hydrocarbon contaminated soils, (2) infections caused by the actinobacterium itself, and (3) marine-derived samples. Obviously, this must not reflect the distribution of surfactant-producing actinobacteria in nature, but it is clear that there is a link between the type of environment and the ability of actinobacteria to produce biosurfactants and can be considered to be environmentally-driven.

\section{Hydrocarbon Contaminated Soil}

The formation of various actinobacterial surfactants is mainly observed during growth in a range of different hydrophobic carbon sources such as n-paraffin, n-hexadecane or vegetable oils. Occurrences of surfactant-producing microorganisms seems to correlate to environments in which hydrophobic carbon sources are present, no matter if these are oil contaminated or oil enriched (Powalla et al., 1989; Arino et al., 1998; Christova et al., 2004, 2014; Pizzul et al., 2006; Liu et al., 2009; Ruggeri et al., 2009). Evoked by their hydrophobic cell wall due to incorporation and association of various lipoglycosides, actinobacteria preferably grow in hydrophobic droplets that are dispersed in the aqueous phase when cultured in cultivation devices. The surfactants produced facilitate the uptake of these difficult-to-access carbon sources by dispersing it into small droplets that can easily be pre-digested by extracellular enzymes.

\section{Infections}

A second feature of surfactants is the antimicrobial property exhibited by most of these compounds. Endowed with nutritional and growth advantages toward surrounding organisms, surfactant producers can become rampant, and are often less affected by substances present during its growth, e.g., antimicrobial drugs. They have been found in patients that suffer from infections/diseases caused by human deficiency viruses (Guérardel et al., 2003), patients with lung infections and infections of the oral cavity (Datta and Takayama, 1993; Sutcliffe, 1995; Tanaka et al., 1997). In addition, biosurfactant-producing actinobacterial strains have also been isolated from infected plant tissue (Frahn et al., 1984).

\section{Marine Habitat}

Many actinobacteria are specialists in survival and native to a wide range of extreme environments. Surfactant-producing genera have been isolated from various marine-associated habitats (Passeri et al., 1990; Khopade et al., 2011; Nakano et al., 2011). 
Several of these environments exhibit rather extreme conditions, amongst which are deep sea sediments or hydrothermal fields (Peng et al., 2008; Konishi et al., 2014; Wang et al., 2014), ornithogenic exposed soil (Vasileva-Tonkova and Gesheva, 2005) as well as actinobacteria isolated from sponges (Gandhimathi et al., 2009; Kiran et al., 2010a,b,c, 2014) and hard corals (Osawa et al., 2010). An antimicrobial effect of surfactants produced in a highly procaryotic populated sponge tissue is apparent. However, the reason for the frequent occurrence of surfactant producers within the other marine habitats, still remains to be understood.

\section{Summary and Conclusion}

A wide range of unique and diverse surfactants produced by actinobacteria have been reported. Various glycolipids, lipopeptides and other surfactant types are produced by numerous species, all belonging to the order Actinomycetales. Taking into account the fact that only a minority of actinobacteria is culturable and the given list of surfactant producing strains without structurally elucidated compounds (Table 11), the sheer magnitude of actinobacterial surfactants that still remain undetermined is evident. The ability of actinobacteria to produce biosurfactants seems to be influenced by their natural habitat. From the three main sources of surfactant producing actinobacteria it can be concluded that the compounds produced mainly serve for either gaining access to hydrophobic carbon sources or as a bioactive agent against competing strains.

In order to pave the way toward biotechnological applications of actinobacterial surfactants, emphasis should be placed on (1) structural elucidation of described, but not identified biosurfactants, (2) the identification of novel actinobacterial surfactants by the implementation of next generation screening methods; (3) the production of sufficient amounts of surfactants for application based studies; and (4) production processes that result in high yields and that would cut down on the production costs.

(1) Actinobacterial strains with a surface active culture broth or supernatant often are declared as "novel" biosurfactant producing strains, without elucidation of the surface active compound(s) produced and a list of producing strains is given in this article whose surfactant structures remain to be identified (Table 11). For a successful structural identification of the compound, sufficient quantities of the isolated surface active compound at an adequate purity is necessary in order to apply the various analytical methods necessary. This aspect was reviewed in the structural elucidation of actinobacterial compounds section. Quite a few of the studies cited lacked sufficient strain information and further research can only be ensured if the strains reported have designated strain numbers and thus are available for other researchers to pursue the production of these potentially novel biosurfactants.

(2) Approaches for the identification of novel biosurfactants mainly remain traditional by the detection of interesting producing strains and subsequent isolation and characterization of the compound produced. To further expand the variety of actinobaterial surfactants, alternative screening methodologies that are already known to be used for the detection of novel lead molecules in the pharmaceutical industry could be applied. Genome-based information technology to reveal pathways that can be implemented into artificial surfactant synthesis cascades are currently being investigated. These attempts would allow for access to both undetected and cryptic pathways present in actinobacteria. By direct sequencing of metagenomic derived DNA, enzyme information acquired could be expanded to information gained from non-culturable and slow growing species.

(3) Many of the surface active compounds produced by actinobacteria potentially show interesting properties as biotechnological products or additives. Often, as is the case for many of the compounds summarized in this article, an application based study is lacking. This is most probably due to low availability of the product and can be traced back to the use of low quantity producing strains. Focus on a novel actinobacterial surfactant, along with progress in the development toward novel biotechnology-based products, will only be made possible if enough substance for initial studies on bioactivity or other interesting applications can be acquired. If an adequate amount of substance is not achievable by standard bioprocess engineering attempts, metabolomic approaches and flux analysis could lead the way. Furthermore, the identification of enzymes involved in the synthesis and their genetic regulation can give an important input into the improvement of fermentation processes. An implementation of the surfactant's synthesis through adequate heterologous production strains could lead to higher quantities of the different surfactants produced. Potential applications of a novel compound is a guarantee of success in white biotechnology and negates the efforts made with regards to its production, purification and elucidation.

(4) Currently, comparatively high production costs combined with low production yields restrict the development of compounds as valuable products, and are mainly limited to high purity applications, e.g., the drug industry. Several examples in the past have shown that once a potential application for a specific compound is foreseen, intensive research is set in motion to facilitate production and purification processes, cutting costs, enhancing yields and, although research often lasts for decades, compounds might end in industrial scale production and application.

One example of an actinobacterial surfactant that successfully underwent the process from detection to application is the antimicrobial agent daptomycin. It was initially produced semisynthetically in a three step procedure, but later a direct synthesis of daptomycin was achieved by feeding toxic decanoic acid to a carbon-limited production culture (Huber et al., 1988). Production rates were further increased by $10-30 \%$ by using a mixture of less toxic decanal and a solvent to solubilize the hydrophobic 
carbon feed (Bertetti et al., 2012). Mutagenesis approaches (Yu et al., 2011; Li et al., 2013), genome shuffling (Yu et al., 2014) and directed overexpression (Huang et al., 2012), have recently led to further increases in production yields. Other examples of success stories, are non-actinobacterial surfactants that have been pushed to application: sophorolipids, mannosyl erythritol lipids and the lipopeptide surfactin have found application in cosmetic industries (Fracchia et al., 2014). Sophorolipids are even applied in low cost cleaning products.

Actinobacteria clearly represents a unique and vast untapped resource for the discovery of novel and potentially useful biosurfactants. The surfactants produced by members of the class Actinobacteria are a highly interesting group of products that could be of great importance in the future in both the area of basic research and application-oriented industrial research.

\section{References}

Abdelmohsen, U. R., Bayer, K., and Hentschel, U. (2014). Diversity, abundance and natural products of marine sponge-associated actinomycetes. Nat. Prod. Rep. 31, 381-399. doi: 10.1039/c3np70111e

Arino, S., Marchal, R., and Vandecasteele, J.-P. (1998). Production of new extracellular glycolipids by a strain of Cellulomonas cellulans (Oerskovia xanthineolytica) and their structural characterization. Can. J. Microbiol. 44, 238-243. doi: $10.1139 /$ w97-156

Arpin, N., Liaaen-Jensen, S., and Trouilloud, M. (1972). Bacterial carotenoids. XXXVIII. C 50-Carotenoids. 9. Isolation of decaprenoxanthin mono-and diglucoside from an Arthrobacter sp. Acta Chem. Scand. 26, 2524-2526.

Asselineau, C., and Asselineau, J. (1978). Trehalose-containing glycolipids. Prog. Chem. Fats Other Lipids 16, 59-99. doi: 10.1016/0079-6832(78)90037-X

Asselineau, J., and Lanéelle, G. (1998). Mycobacterial lipids: a historical perspective. Front. Biosci. 3, e164-e174.

Azuma, M., Suzutani, T., Sazaki, K., Yoshida, I., Sakuma, T., and Yoshida, T. (1987). Role of interferon in the augmented resistance of trehalose-6, 6'dimycolate-treated mice to influenza virus infection. J. Gen. Virol. 68, 835-843. doi: 10.1099/0022-1317-68-3-835

Baltz, R. H. (2008). Renaissance in antibacterial discovery from actinomycetes. Curr. Opin. Pharmacol. 8, 557-563. doi: 10.1016/j.coph.2008.04.008

Berdy, J. (2005). Bioactive microbial metabolites. J. Antibiot. 58, 1-26. doi: $10.1038 /$ ja.2005.1

Bérdy, J. (2012). Thoughts and facts about antibiotics: where we are now and where we are heading. J. Antibiot. 65, 385-395. doi: 10.1038/ja.2012.27

Berg, S., Kaur, D., Jackson, M., and Brennan, P. J. (2007). The glycosyltransferases of Mycobacterium tuberculosis-roles in the synthesis of arabinogalactan, lipoarabinomannan, and other glycoconjugates. Glycobiology 17, 35R-56R. doi: $10.1093 /$ glycob/cwm010

Bertetti, G., Malcangi, A., Muraca, R., Trione, G., and Rossi, A. (2012). Process for the Production of Daptomycin. United states Patent 8, 313,922. Washington, DC: U.S. Patent and Trademark Office.

Brennan, P. (2003). Structure, function, and biogenesis of the cell wall of Mycobacterium tuberculosis. Tuberculosis 83, 91-97. doi: 10.1016/S1472-9792(02)000896

Brennan, P. J. (1989). Structure of mycobacteria: recent developments in defining cell wall carbohydrates and proteins. Rev. Infec. Dis. 11, S420-S430. doi: 10.1093/clinids/11.Supplement_2.S420

Brennan, P. J., Lehane, D. P., and Thomas, D. W. (1970). Acylglucoses of the Corynebacteria and Mycobacteria. Eur. J. Biochem. 13, 117-123. doi: 10.1111/j.1432-1033.1970.tb00906.x

Briken, V., Porcelli, S. A., Besra, G. S., and Kremer, L. (2004). Mycobacterial lipoarabinomannan and related lipoglycans: from biogenesis to modulation of the immune response. Mol. Microbiol. 53, 391-403. doi: 10.1111/j.13652958.2004.04183.x

\section{Author Contributions}

JK has designed, conceived, and written this review, it's figures and tables as well as acquired and interpreted the relevant data used. All authors have fruitfully discussed content and structure of the review. In particular, ML has given substantial contributions related to actinobacteria and CS and $\mathrm{RH}$ have given substantial contributions related to biosurfactants.

\section{Acknowledgments}

We acknowledge support by Deutsche Forschungsgemeinschaft and Open Access Publishing Fund of Karlsruhe Institute of Technology, Germany.

Chatterjee, D., and Khoo, K.-H. (1998). Mycobacterial lipoarabinomannan: an extraordinary lipoheteroglycan with profound physiological effects. Glycobiol$\operatorname{og} y$ 8, 113-120. doi: 10.1093/glycob/8.2.113

Christofi, N., and Ivshina, I. (2002). Microbial surfactants and their use in field studies of soil remediation. J. Appl. Microbiol. 93, 915-929. doi: 10.1046/j.13652672.2002.01774.x

Christova, N., Lang, S., Wray, V., Kaloyanov, K., Konstantinov, S., and Stoineva, I. (2014). Production, structural elucidation and in vitro antitumor activity of trehalose lipid biosurfactant from Nocardia farcinica strain. J. Microbiol. Biotechnol. doi: 10.4014/jmb.1406.06025. [Epub ahead of print].

Christova, N., Tuleva, B., Lalchev, Z., Jordanova, A., and Jordanov, B. (2004). Rhamnolipid biosurfactants produced by Renibacterium salmoninarum $27 \mathrm{BN}$ during growth on n-hexadecane. Z. Naturforsch C 59, 70-74. doi: 10.1515/znc2004-1-215

Ciabatti, R., Kettenring, J., Winters, G., Tuan, G., Zerilli, L., and Cavalleri, B. (1989). Ramoplanin (A-16686), a new glycolipodepsipeptide antibiotic. III. Structure elucidation. J. Antibiot. 42, 254-267. doi: 10.7164/antibiotics.42.254

Colin, V. L., Castro, M. F., Amoroso, M. J., and Villegas, L. B. (2013). Production of bioemulsifiers by Amycolatopsis tucumanensis DSM 45259 and their potential application in remediation technologies for soils contaminated with hexavalent chromium. J. Hazard. Mater. 261, 577-583. doi: 10.1016/j.jhazmat.2013. 08.005

Cooper, D. G., Zajic, J. E., and Gerson, D. F. (1979a). Production of surface-active lipids by Corynebacterium lepus. Appl. Environ. Microbiol. 37, 4-10.

Cooper, D. G., Zajic, J. E., and Gracey, D. (1979b). Analysis of corynomycolic acids and other fatty acids produced by Corynebacterium lepus grown on kerosene. J. Bacteriol. 137, 795-801.

Daniel, H.-J., Reuss, M., and Syldatk, C. (1998). Production of sophorolipids in high concentration from deproteinized whey and rapeseed oil in a two stage fed batch process using Candida bombicola ATCC 22214 and Cryptococcus curvatus ATCC 20509. Biotechnol. Lett. 20, 1153-1156. doi: 10.1023/A:1005332 605003

Datta, A. K., and Takayama, K. (1993). Isolation and purification of trehalose 6-mono-and 6,6'-di-corynomycolates from Corynebacterium matruchotii. Structural characterization by $1 \mathrm{H}$ NMR. Carbohyd. Res. 245, 151-158. doi: 10.1016/0008-6215(93)80068-P

Debono, M., Barnhart, M., Carrell, C., Hoffmann, J., Occolowitz, J., Abbott, B., et al. (1987). A21978C, a complex of new acidic peptide antibiotics: isolation, chemistry, and mass spectral structure elucidation. J. Antibiot. 40, 761-777. doi: 10.7164/antibiotics.40.761

Dembitsky, V. M. (2004). Astonishing diversity of natural surfactants: 1. Glycosides of fatty acids and alcohols. Lipids 39, 933-953. doi: 10.1007/s11745-0041316-1

Dembitsky, V. M. (2005a). Astonishing diversity of natural surfactants: 2 . Polyether glycosidic ionophores and macrocyclic glycosides. Lipids 40, 219-248. doi: 10.1007/s11745-005-1378-0 
Dembitsky, V. M. (2005b). Astonishing diversity of natural surfactants: 3 . Carotenoid glycosides and isoprenoid glycolipids. Lipids 40, 535-557. doi: $10.1007 /$ s11745-005-1415-z

Dembitsky, V. M. (2005c). Astonishing diversity of natural surfactants: 4. Fatty acid amide glycosides, their analogs and derivatives. Lipids 40, 641-660. doi: 10.1007/s11745-005-1427-8

Domenech, P., Reed, M. B., Dowd, C. S., Manca, C., Kaplan, G., and Barry, C. E. (2004). The role of MmpL8 in sulfatide biogenesis and virulence of Mycobacterium tuberculosis. J. Biol. Chem. 279, 21257-21265. doi: 10.1074/jbc.M400324200

Doshi, D. V., Maniyar, J. P., Bhuyan, S. S., and Mujumdar, S. S. (2010). Studies on bioemulsifier production by Actinopolyspora sp. A 18 isolated from garden soil. Indian J. Biotechnol. 9, 391-396. Available online at: http://nopr.niscair.res.in/handle/123456789/10437

Embley, T., and Stackebrandt, E. (1994). The molecular phylogency and systematics of the actinomycetes. Annu. Rev. Microbiol. 48, 257-289. doi: 10.1146/annurev.mi.48.100194.001353

Esch, S. W., Morton, M. D., Williams, T. D., and Buller, C. S. (1999). A novel trisaccharide glycolipid biosurfactant containing trehalose bears ester-linked hexanoate, succinate, and acyloxyacyl moieties: NMR and MS characterization of the underivatized structure. Carbohyd. Res. 319, 112-123. doi: 10.1016/S00086215(99)00122-6

Euzéby, J. (2012). Validation List No. 144 List of new names and new combinations previously effectively, but not validly, published. Int. J. Syst. Evol. Microbiol. 62, 473-475. doi: 10.1099/ijs.0.041269-0

Euzéby, J. (2013). Validation List No. 151 List of new names and new combinations previously effectively, but not validly, published. Int. J. Syst. Evol. Microbiol. 63, 1577-1580. doi: 10.1099/ijs.0.052571-0

Flaherty, C., and Sutcliffe, I. C. (1999). Identification of a lipoarabinomannan-like lipoglycan in Gordonia rubropertincta. Syst. Appl. Microbiol. 22, 530-533. doi: 10.1016/S0723-2020(99)80005-8

Fracchia, L., Ceresa, C., Franzetti, A., Cavallo, M., Gandolfi, I., Van Hamme, J., et al. (2014). Industrial applications of biosurfactants. Biosurfactants: Production and Utilization-Processes, Technologies, and Economics, eds N. Kosaric and F. Vardar-Sukan (Boca Raton; London; New York: CRC Press; Taylor \& Francis Group), 159, 245. doi: 10.1201/b17599-15

Frahn, J., Edgar, J., Jones, A., Cockrum, P., Anderton, N., and Culvenor, C. (1984). Structure of the corynetoxins, metabolites of Corynebacterium rathayi responsible for toxicity of annual ryegrass (Lolium rigidum) pastures. Aust. J. Chem. 37, 165-182. doi: 10.1071/CH9840165

Franzetti, A., Gandolfi, I., Bestetti, G., Smyth, T. J., and Banat, I. M. (2010). Production and applications of trehalose lipid biosurfactants. Eur. J. Lipid Sci. Technol. 112, 617-627. doi: 10.1002/ejlt.200900162

Gamian, A., Mordarska, H., Ekiel, I., Ulrich, J., Szponar, B. A., and Defaye, J. (1996). Structural studies of the major glycolipid from Saccharopolyspora genus. Carbohyd. Res. 296, 55-67. doi: 10.1016/S0008-6215(96)00246-7

Gandhimathi, R., Kiran, G. S., Hema, T. A., Selvin, J., Raviji, T. R., and Shanmughapriya, S. (2009). Production and characterization of lipopeptide biosurfactant by a sponge-associated marine actinomycetes Nocardiopsis alba MSA10. Bioprocess Biosyst. Eng. 32, 825-835. doi: 10.1007/s00449-009-0309-x

Garton, N. J., and Sutcliffe, I. C. (2006). Identification of a lipoarabinomannanlike lipoglycan in the actinomycete Gordonia bronchialis. Arch. Microbiol. 184, 425-427. doi: 10.1007/s00203-005-0050-z

Gastaldo, L., Ciabatti, R., Assi, F., Restelli, E., Kettenring, J. K., Zerilli, L. F., et al. (1992). Isolation, structure determination and biological activity of A-16686 factors A' 1, A' 2 and A' 3 glycolipodepsipeptide antibiotics. J. Ind. Microbiol. 11, 13-18. doi: 10.1007/BF01583726

Gautier, N., Marín, L. M. L., Lanéelle, M.-A., and Daffé, M. (1992). Structure of mycoside F, a family of trehalose-containing glycolipids of Mycobacterium fortuitum. FEMS Microbiol. Lett. 98, 81-87. doi: 10.1111/j.15746968.1992.tb05494.x

Gesheva, V., Stackebrandt, E., and Vasileva-Tonkova, E. (2010). Biosurfactant production by halotolerant Rhodococcus fascians from Casey station, Wilkes land, Antarctica. Curr. Microbiol. 61, 112-117. doi: 10.1007/s00284-0109584-7

Giani, C., Wullbrandt, D., Rothert, R., and Meiwes, J. (1996). Pseudomonas Aeruginosa and its Use in a Process for the Biotechnological Preparation of L-rhamnose. United states Patent 5,501,966. Washington, DC: U.S. Patent and Trademark Office.
Gibson, K. J., Gilleron, M., Constant, P., Brando, T. R. S., Puzo, G., Besra, G. S., et al. (2004). Tsukamurella paurometabola lipoglycan, a new lipoarabinomannan variant with pro-inflammatory activity. J. Biol. Chem. 279, 22973-22982. doi: 10.1074/jbc.M310906200

Gibson, K. J., Gilleron, M., Constant, P., Puzo, G., Nigou, J., and Besra, G. S. (2003). Identification of a novel mannose-capped lipoarabinomannan from Amycolatopsis sulphurea. Biochem. J. 372, 821-829. doi: 10.1042/BJ20030197

Gill, K. A., Berrué, F., Arens, J. C., and Kerr, R. G. (2014). Isolation and structure elucidation of Cystargamide, a lipopeptide from Kitasatospora cystarginea. J. Nat. Prod. 77, 1372-1376. doi: 10.1021/np500122s

Gilleron, M., Garton, N. J., Nigou, J. R. M., Brando, T. R. S., Puzo, G., and Sutcliffe, I. C. (2005). Characterization of a truncated lipoarabinomannan from the Actinomycete Turicella otitidis. J. Bacteriol. 187, 854-861. doi: 10.1128/JB.187.3.854-861.2005

Gilleron, M., Stenger, S., Mazorra, Z., Wittke, F., Mariotti, S., Böhmer, G., et al. (2004). Diacylated sulfoglycolipids are novel mycobacterial antigens stimulating CD1-restricted T cells during infection with Mycobacterium tuberculosis. J. Exp. Med. 199, 649-659. doi: 10.1084/jem.20031097

Goodfellow, M., and Fiedler, H.-P. (2010). A guide to successful bioprospecting: informed by actinobacterial systematics. Antonie Van Leeuwenhoek 98 , 119-142. doi: 10.1007/s10482-010-9460-2

Goren, M. B. (1970). Sulfolipid I of Mycobacterium tuberculosis, strain H37Rv II. Structural studies. Biochim. Biophys. Acta 210, 127-138. doi: 10.1016/00052760(70)90068-8

Gudiña, E. J., Rangarajan, V., Sen, R., and Rodrigues, L. R. (2013). Potential therapeutic applications of biosurfactants. Trends Pharmacol. Sci. 34, 667-675. doi: 10.1016/j.tips.2013.10.002

Guérardel, Y., Maes, E., Briken, V., Chirat, F., Leroy, Y., Locht, C., et al. (2003). Lipomannan and lipoarabinomannan from a clinical isolate of Mycobacterium kansasii novel structural features and apoptosisinducing properties. J. Biol. Chem. 278, 36637-36651. doi: 10.1074/jbc.M30 5427200

Hausmann, R., and Syldatk, C. (2014). "Types and classification of microbial surfactants," in Biosurfactants: Production and Utilization-Processes, Technologies, and Economics, Vol. 159, eds N. Kosaric and F. Vardar-Sukan (Boca Raton; London; New York: CRC Press; Taylor \& Francis Group), 1.

Haydock, S. F., Mironenko, T., Ghoorahoo, H. I., and Leadlay, P. F. (2004). The putative elaiophylin biosynthetic gene cluster in Streptomyces sp. DSM4137 is adjacent to genes encoding adenosylcobalamin-dependent methylmalonyl CoA mutase and to genes for synthesis of cobalamin. J. Biotechnol. 113, 55-68. doi: 10.1016/j.jbiotec.2004.03.022

Henkel, M., Müller, M. M., Kügler, J. H., Lovaglio, R. B., Contiero, J., Syldatk, C., et al. (2012). Rhamnolipids as biosurfactants from renewable resources: Concepts for next-generation rhamnolipid production. Process Biochem. 47, 1207-1219. doi: 10.1016/j.procbio.2012.04.018

Hopmann, C., Kurz, M., Brönstrup, M., Wink, J., and Lebeller, D. (2002). Isolation and structure elucidation of vancoresmycin - a new antibiotic from Amycolatopsis sp. ST 101170. Tetrahedron. Lett. 43, 435-438. doi: 10.1016/S00404039(01)02171-2

Huang, D., Wen, J., Wang, G., Yu, G., Jia, X., and Chen, Y. (2012). In silico aided metabolic engineering of Streptomyces roseosporus for daptomycin yield improvement. Appl. Microbiol. Biotechnol. 94, 637-649. doi: 10.1007/s00253011-3773-6

Huber, F., Pieper, R., and Tietz, A. (1988). The formation of daptomycin by supplying decanoic acid to Streptomyces roseosporus cultures producing the antibiotic complex A21978C. J. Biotechnol. 7, 283-292. doi: 10.1016/0168-1656(88) 90040-5

Ishikawa, E., Ishikawa, T., Morita, Y. S., Toyonaga, K., Yamada, H., Takeuchi, O., et al. (2009). Direct recognition of the mycobacterial glycolipid, trehalose dimycolate, by C-type lectin Mincle. J. Exp. Med. 206, 2879-2888. doi: $10.1084 /$ jem. 20091750

Isoda, H., Kitamoto, D., Shinmoto, H., Matsumura, M., and Nakahara, T. (1997). Microbial extracellular glycolipid induction of differentiation and inhibition of protein kinase $\mathrm{C}$ activity of human promyelocytic leukaemia cell line HL60. Biosci. Biotechnol. Biochem. 61, 609-614. doi: 10.1271/ bbb.61.609

Itoh, S., and Suzuki, T. (1974). Fructose-lipids of Arthrobacter, Corynebacteria, Nocardia and Mycobacteria grown on fructose. Agr. Biol. Chem. Tokyo 38, 1443-1449. doi: 10.1271/bbb1961.38.1443 
Iwahori, K., Tokutomi, T., Miyata, N., and Fujita, M. (2001). Formation of stable foam by the cells and culture supernatant of Gordonia (Nocardia) amarae. J. Biosci. Bioeng. 92, 77-79. doi: 10.1016/S1389-1723(01)80203-6

Khan, A. A., Stocker, B. L., and Timmer, M. S. (2012). Trehalose glycolipidssynthesis and biological activities. Carbohyd. Res. 356, 25-36. doi: 10.1016/j.carres.2012.03.010

Khopade, A., Ren, B., Liu, X.-Y., Mahadik, K., Zhang, L., and Kokare, C. (2011). Production and characterization of biosurfactant from marine Streptomyces species B3. J. Colloid Interface Sci. 367, 311-318. doi: 10.1016/j.jcis.2011. 11.009

Kiran, G. S., Sabarathnam, B., Thajuddin, N., and Selvin, J. (2014). Production of glycolipid biosurfactant from sponge-associated marine actinobacterium Brachybacterium paraconglomeratum MSA21. J. Surfactants Deterg. 17, 531-542. doi: 10.1007/s11743-014-1564-7

Kiran, G. S., Sabu, A., and Selvin, J. (2010a). Synthesis of silver nanoparticles by glycolipid biosurfactant produced from marine Brevibacterium casei MSA19. J. Biotechnol. 148, 221-225. doi: 10.1016/j.jbiotec.2010.06.012

Kiran, G. S., Thomas, T. A., and Selvin, J. (2010b). Production of a new glycolipid biosurfactant from marine Nocardiopsis lucentensis MSA04 in solid-state cultivation. Colloids Surf. B Biointerfaces 78, 8-16. doi: 10.1016/j.colsurfb.2010.01.028

Kiran, G. S., Thomas, T. A., Selvin, J., Sabarathnam, B., and Lipton, A. P. (2010c). Optimization and characterization of a new lipopeptide biosurfactant produced by marine Brevibacterium aureum MSA13 in solid state culture. Bioresour. Technol. 101, 2389-2396. doi: 10.1016/j.biortech.2009.11.023

Komatsu, K., Tsuda, M., Tanaka, Y., Mikami, Y., and Kobayashi, J. I. (2004). Absolute stereochemistry of immunosuppressive macrolide brasilinolide A and its new congener brasilinolide C. J. Org. Chem. 69, 1535-1541. doi: 10.1021/jo035773v

Konishi, M., Nishi, S., Fukuoka, T., Kitamoto, D., Watsuji, T.-O., Nagano, Y., et al. (2014). Deep-sea Rhodococcus sp. BS-15, lacking the phytopathogenic fas genes, produces a novel glucotriose lipid biosurfactant. Mar. Biotechnol. (NY) 16, 484-493. doi: 10.1007/s10126-014-9568-X

Kügler, J. H., Muhle-Goll, C., Kühl, B., Kraft, A., Heinzler, R., Kirschhöfer, F., et al. (2014). Trehalose lipid biosurfactants produced by the actinomycetes Tsukamurella spumae and T. pseudospumae. Appl. Microbiol. Biotechnol. 98, 8905-8915. doi: 10.1007/s00253-014-5972-4

Kurtboke, I. (2010). Biodiscovery from microbial resources: actinomycetes leading the way. Microbiol. Aust. 31, 53-56. Available online at: http://microbiology.publish.csiro.au/?paper=MA10053

Kuyukina, M. S., and Ivshina, I. B. (2010). "Rhodococcus biosurfactants: biosynthesis, properties, and potential applications," in Biology of Rhodococcus ed H. M. Alvarez (Berlin, Heidelberg: Springer), 291-313.

Lanéelle, M.-A., and Asselineau, J. (1977). Glycolipids of Brevibacterium vitarumen. Biochim. Biophys. Acta 486, 205-208. doi: 10.1016/0005-2760(77)90085-6

Lang, S., and Philp, J. C. (1998). Surface-active lipids in rhodococci. Antonie Van Leeuwenhoek 74, 59-70. doi: 10.1023/A:1001799711799

Lennarz, W., and Talamo, B. (1966). The chemical characterization and enzymatic synthesis of mannolipids in Micrococcus lysodeikticus. J. Biol. Chem. 241, 2707-2719.

Li, L., Ma, T., Liu, Q., Huang, Y., Hu, C., and Liao, G. (2013). Improvement of daptomycin production in Streptomyces roseosporus through the acquisition of pleuromutilin resistance. Biomed. Res. Int. 2013:479742. doi: $10.1155 / 2013 / 479742$

Liu, J., Huang, X.-F., Lu, L.-J., Xu, J.-C., Wen, Y., Yang, D.-H., et al. (2009). Comparison between waste frying oil and paraffin as carbon source in the production of biodemulsifier by Dietzia sp. S-JS-1. Bioresour. Technol. 100, 6481-6487. doi: 10.1016/j.biortech.2009.07.006

Ludwig, W., and Klenk, H.-P. (2001). "Overview: a phylogenetic backbone and taxonomic framework for procaryotic systematics," in Bergey's Manual of Systematic Bacteriology, eds D. R. Boone, R. W. Castenholz, and G. M. Garrity (New York, NY: Springer), 49-65.

Macdonald, C. R., Cooper, D. G., and Zajic, J. E. (1981). Surface-active lipids from Nocardia erythropolis grown on hydrocarbons. Appl. Environ. Microbiol. 41, $117-123$.

Manivasagan, P., Venkatesan, J., Sivakumar, K., and Kim, S.-K. (2013). Marine actinobacterial metabolites: current status and future perspectives. Microbiol. Res. 168, 311-332. doi: 10.1016/j.micres.2013.02.002
Marchant, R., and Banat, I. M. (2012). Microbial biosurfactants: challenges and opportunities for future exploitation. Trends Biotechnol. 30, 558-565. doi: 10.1016/j.tibtech.2012.07.003

Margaritis, A., Zajic, J., and Gerson, D. (1979). Production and surface-active properties of microbial surfactants. Biotechnol. Bioeng. 21, 1151-1162. doi: 10.1002/bit.260210706

Marques, A., Pinazo, A., Farfan, M., Aranda, F., Teruel, J., Ortiz, A., et al. (2009). The physicochemical properties and chemical composition of trehalose lipids produced by Rhodococcus erythropolis 51T7. Chem. Phys. Lipids 158, 110-117. doi: 10.1016/j.chemphyslip.2009.01.001

Miao, V., Coeffet-Legal, M.-F., Brian, P., Brost, R., Penn, J., Whiting, A., et al. (2005). Daptomycin biosynthesis in Streptomyces roseosporus: cloning and analysis of the gene cluster and revision of peptide stereochemistry. Microbiology 151, 1507-1523. doi: 10.1099/mic.0.27757-0

Mikami, Y., Komaki, H., Imai, T., Yazawa, K., Nemoto, A., Tanaka, Y., et al. (2000). A new antifungal macrolide component, brasilinolide B, produced by Nocardia brasiliensis. J. Antibiot. 53:70. doi: 10.7164/antibiotics.53.70

Mordarska, H., Gamian, A., and Ekiel, I. (1992). Structural studies of major glycolipids from Curtobacterium flaccumfaciens pathovar betae and Rothia dentocariosa. Actinomycetes 3, 31-36.

Morikawa, M., Daido, H., Takao, T., Murata, S., Shimonishi, Y., and Imanaka, T. (1993). A new lipopeptide biosurfactant produced by Arthrobacter sp. strain MIS38. J. Bacteriol. 175, 6459-6466.

Morita, T., Konishi, M., Fukuoka, T., Imura, T., Sakai, H., and Kitamoto, D. (2008). Efficient production of di- and tri-acylated mannosylerythritol lipids as glycolipid biosurfactants by Pseudozyma parantarctica JCM $11752^{\mathrm{T}}$. J. Oleo Sci. 57, 557-565. doi: 10.5650/jos.57.557

Müller, M. M., Kügler, J. H., Henkel, M., Gerlitzki, M., Hörmann, B., Pöhnlein, M., et al. (2012). Rhamnolipids-next generation surfactants? J. Biotechnol. 162, 366-380. doi: 10.1016/j.jbiotec.2012.05.022

Nakano, M., Kihara, M., Iehata, S., Tanaka, R., Maeda, H., and Yoshikawa, T. (2011). Wax ester-like compounds as biosurfactants produced by Dietzia maris from n-alkane as a sole carbon source. J. Basic Microbiol. 51, 490-498. doi: 10.1002/jobm.201000420

Niepel, T., Meyer, H., Wray, V., and Abraham, W.-R. (1997). A new type of glycolipid, 1-[ $\alpha$-mannopyranosyl-(1 $\alpha-3)-(6-\mathrm{O}$-acyl- $\alpha$-mannopyranosyl)]-3-Oacylglycerol, from Arthrobacter atrocyaneus. Tetrahedron 53, 3593-3602. doi: 10.1016/S0040-4020(97)00079-3

Nigou, J. R. M., Gilleron, M., and Puzo, G. (2003). Lipoarabinomannans: from structure to biosynthesis. Biochimie 85, 153-166. doi: 10.1016/S03009084(03)00048-8

Okazaki, H., Sugino, H., Kanzaki, T., Fukuda, H., and Isobe, K. (1969). l-glutamic acid fermentation: Part VI. structure of a sugar lipid produced by Brevibacterium thiogenitalis Part VII. Relation between biotin and oleic acid. Agr. Biol. Chem. Tokyo 33, 764-780. doi: 10.1271/bbb1961.33.764

Osawa, A., Ishii, Y., Sasamura, N., Morita, M., Kasai, H., Maoka, T., et al. (2010). Characterization and antioxidative activities of rare $C_{50}$ carotenoidsSarcinaxanthin, Sarcinaxanthin monoglucoside, and Sarcinaxanthin diglucoside-obtained from Micrococcus yunnanensis. J. Oleo Sci. 59, 653-659. doi: 10.5650 /jos. 59.653

Pakkiri, L. S., and Waechter, C. J. (2005). Dimannosyldiacylglycerol serves as a lipid anchor precursor in the assembly of the membrane-associated lipomannan in Micrococcus luteus. Glycobiology 15, 291-302. doi: 10.1093/glycob/cwi003

Pasciak, M., Ekiel, I., Grzegorzewicz, A., Mordarska, H., and Gamian, A. (2002). Structure of the major glycolipid from Rothia dentocariosa. Biochim. Biophys. Act 1594, 199-205. doi: 10.1016/S0167-4838(01)00301-6

Pasciak, M., Holst, O., Lindner, B., Mierzchala, M., Grzegorzewicz, A., Mordarska, H., et al. (2004). Structural and serological characterization of the major glycolipid from Rothia mucilaginosa. Biochim. Biophys. Act 1675, 54-61. doi: 10.1016/j.bbagen.2004.08.004

Pasciak, M., Kaczynski, Z., Lindner, B., Holst, O., and Gamian, A. (2010a). Immunochemical studies of trehalose-containing major glycolipid from Tsukamurella pulmonis. Carbohyd. Res. 345, 1570-1574. doi: 10.1016/j.carres.2010.04.026

Pasciak, M., Sanchez-Carballo, P., Duda-Madej, A., Lindner, B., Gamian, A., and Holst, O. (2010b). Structural characterization of the major glycolipids from Arthrobacter globiformis and Arthrobacter scleromae. Carbohyd. Res. 345, 1497-1503. doi: 10.1016/j.carres.2010.03.014 
Passeri, A., Lang, S., Wagner, F., and Wray, V. (1990). Marine biosurfactants, II. Production and characterization of an anionic trehalose tetraester from the marine bacterium Arthrobacter sp. EK 1. Z. Naturforsch 46, 204-209.

Pathirana, C., Jensen, P. R., Dwight, R., and Fenical, W. (1992). Rare phenazine Lquinovose esters from a marine actinomycete. J. Org. Chem. 57, 740-742. doi: 10.1021/jo00028a060

Peng, F., Wang, Y., Sun, F., Liu, Z., Lai, Q., and Shao, Z. (2008). A novel lipopeptide produced by a Pacific Ocean deep-sea bacterium, Rhodococcus sp. TW53. J. Appl. Microbiol. 105, 698-705. doi: 10.1111/j.1365-2672.2008.03816.x

Philp, J., Kuyukina, M., Ivshina, I., Dunbar, S., Christofi, N., Lang, S., et al. (2002). Alkanotrophic Rhodococcus ruber as a biosurfactant producer. Appl. Microbiol. Biotechnol. 59, 318-324. doi: 10.1007/s00253-002-1018-4

Pizzul, L., Pilar Castillo, M. D., and Stenström, J. (2006). Characterization of selected actinomycetes degrading polyaromatic hydrocarbons in liquid culture and spiked soil. World J. Microbiol. Bioechnol. 22, 745-752. doi: 10.1007/s11274-005-9100-6

Powalla, M., Lang, S., and Wray, V. (1989). Penta-and disaccharide lipid formation by Nocardia corynebacteroides grown on n-alkanes. Appl. Microbiol. Biotechnol. 31, 473-479. doi: 10.1007/BF00270779

Qian-Cutrone, J., Ueki, T., Huang, S., Mookhtiar, K. A., Ezekiel, R., Kalinowski, S. S., et al. (1999). Glucolipsin A and B, two new glucokinase activators produced by Streptomyces purpurogeniscleroticus and Nocardia vaccinii. J. Antibiot. 52, 245-255. doi: 10.7164/antibiotics.52.245

Richter, M., Willey, J. M., Süßmuth, R., Jung, G., and Fiedler, H.-P. (1998). Streptofactin, a novel biosurfactant with aerial mycelium inducing activity from Streptomyces tendae Tü 901/8c. FEMS Microbiol. Lett. 163, 165-171. doi: 10.1111/j.1574-6968.1998.tb13041.x

Ristau, E., and Wagner, F. (1983). Formation of novel anionic trehalosetetraesters from Rhodococcus erythropolis under growth limiting conditions. Biotechnol. Lett. 5, 95-100. doi: 10.1007/BF00132166

Roongsawang, N., Hase, K.-I., Haruki, M., Imanaka, T., Morikawa, M., and Kanaya, S. (2003). Cloning and characterization of the gene cluster encoding arthrofactin synthetase from Pseudomonas sp. MIS38. Chem. Biol. 10, 869-880. doi: 10.1016/j.chembiol.2003.09.004

Ruggeri, C., Franzetti, A., Bestetti, G., Caredda, P., La Colla, P., Pintus, M., et al. (2009). Isolation and characterisation of surface active compoundproducing bacteria from hydrocarbon-contaminated environments. Int. Biodeterior. Biodegradation 63, 936-942. doi: 10.1016/j.ibiod.2009.05.003

Saadat, S., and Ballou, C. (1983). Pyruvylated glycolipids from Mycobacterium smegmatis. Structures of two oligosaccharide components. J. Biol. Chem. 258, 1813-1818.

Saeki, H., Sasaki, M., Komatsu, K., Miura, A., and Matsuda, H. (2009). Oil spill remediation by using the remediation agent JE1058BS that contains a biosurfactant produced by Gordonia sp. strain JE-1058. Bioresour. Technol. 100, 572-577. doi: 10.1016/j.biortech.2008.06.046

Saimmai, A., Rukadee, O., Onlamool, T., Sobhon, V., and Maneerat, S. (2012a). Characterization and phylogenetic analysis of microbial surface active compound-producing bacteria. Appl. Biochem. Biotechnol. 168, 1003-1018. doi: 10.1007/s12010-012-9836-Z

Saimmai, A., Sobhon, V., and Maneerat, S. (2012b). Production of biosurfactant from a new and promising strain of Leucobacter komagatae 183. Ann. Microbiol. 62, 391-402. doi: 10.1007/s13213-011-0275-9

Sarafin, Y., Donio, M. B. S., Velmurugan, S., Michaelbabu, M., and Citarasu, T. (2014). Kocuria marina BS-15 a biosurfactant producing halophilic bacteria isolated from solar salt works in India. Saudi J. Biol. Sci. 21, 511-519. doi: 10.1016/j.sjbs.2014.01.001

Satpute, S. K., Banpurkar, A. G., Dhakephalkar, P. K., Banat, I. M., and Chopade, B. A. (2010). Methods for investigating biosurfactants and bioemulsifiers: a review. Crit. Rev. Biotech. 30,127-144. doi: 10.3109/0738855090 3427280

Shao, Z. (2011). "Trehalolipids," in Biosurfactants-From Genes to Applications, ed G. Soberón-Chávez (Berlin; Heidelberg: Springer), 121-143.

Shaw, N. (1970). Bacterial glycolipids. Bacteriol. Rev. 34, 365.

Singer, M. V., Finnerty, W., and Tunelid, A. (1990). Physical and chemical properties of a biosurfactant synthesized by Rhodococcus species H13-A. Can. J. Microbiol. 36, 746-750. doi: 10.1139/m90-128

Sudo, T., Zhao, X., Wakamatsu, Y., Shibahara, M., Nomura, N., Nakahara, T., et al. (2000). Induction of the differentiation of human HL-60 promyelocytic leukemia cell line by succinoyl trehalose lipids. Cytotechnology 33, 259-264. doi: 10.1023/A:1008137817944

Sutcliffe, I. C. (1995). Identification of a lipoarabinomannan-like lipoglycan in Corynebacterium matruchotii. Arch. Oral Biol. 40, 1119-1124. doi: 10.1016/0003-9969(95)00086-0

Sutcliffe, I. C. (1997). Macroamphiphilic cell envelope components of Rhodococcus equi and closely related bacteria. Vet. Microbiol. 56, 287-299. doi: 10.1016/S0378-1135(97)00097-7

Sutcliffe, I. C. (2000). Characterisation of a lipomannan lipoglycan from the mycolic acid containing actinomycete Dietzia maris. Antonie Van Leeuwenhoek 78, 195-201. doi: 10.1023/A:1026562610490

Suzuki, T., Tanaka, H., and Itoh, S. (1974). Sucrose lipids of Arthrobacteria, Corynebacteria and Nocardia grown on sucrose. Agric. Biol. Chem. 38, 557-563. doi: 10.1271/bbb1961.38.557

Suzuki, T., Tanaka, K., Matsubara, I., and Kinoshita, S. (1969). Trehalose lipid and $\alpha$-branched- $\beta$-hydroxy fatty acid formed by bacteria grown on n-alkanes. Agr. Biol. Chem. Tokyo 33, 1619-1627. doi: 10.1271/bbb1961.33.1619

Tabuchi, T., Nakamura, I., Higashi, E., and Kobayashi, H. (1977). Factors affecting the production of the open-ring acid of spiculisporic acid by Penicillium spiculisporum. J. Ferment Technol. 55, 43-49.

Takaichi, S., Tamura, Y., Azegami, K., Yamamoto, Y., and Ishidsu, J.-I. (1997). Carotenoid glucoside mycolic acid esters from the nocardioform actinomycetes, Rhodococcus rhodochrous. Phytochemistry 45, 505-508. doi: 10.1016/S0031-9422(97)00002-2

Takizawa, M., Hida, T., Horiguchi, T., Hiramoto, A., Harada, S., and Tanida, S. (1995). TAN-1511 A, B and C, microbial lipopeptides with G-CSF and GM-CSF inducing activity. J. Antibiot. 48, 579-588. doi: 10.7164/antibiotics.48.579

Tanaka, Y., Komaki, H., Yazawa, K., Mikami, Y., Nemoto, A., Tojyo, T., et al. (1997). Brasilinolide A, a new macrolide antibiotic produced by Nocardia brasiliensis: producing strain, isolation and biological activity. J. Antibiot. 50, 1036-1041. doi: 10.7164/antibiotics.50.1036

Tokumoto, Y., Nomura, N., Uchiyama, H., Imura, T., Morita, T., Fukuoka, T., et al. (2009). Structural characterization and surface-active properties of a succinoyl trehalose lipid produced by Rhodococcus sp. SD-74. J. Oleo Sci. 58, 97-102. doi: $10.5650 /$ jos.58.97

Tsunakawa, M., Komiyama, N., Tenmyo, O., Tomita, K., Kawano, K., Kotake, C., et al. (1992a). New antiviral antibiotics, cycloviracins B1 and B2. I. Production, isolation, physico-chemical properties and biological activity. J. Antibiot. 45, 1467-1471. doi: 10.7164/antibiotics.45.1467

Tsunakawa, M., Kotake, C., Yamasaki, T., Moriyama, T., Konishi, M., and Oki, T. (1992b). New antiviral antibiotics, cycloviracins B1 and B2. II. Structure determination. J. Antibiot. 45, 1472-1480. doi: 10.7164/antibiotics.45.1472

Tuleva, B., Christova, N., Cohen, R., Antonova, D., Todorov, T., and Stoineva, I. (2009). Isolation and characterization of trehalose tetraester biosurfactants from a soil strain Micrococcus luteus BN56. Process Biochem. 44, 135-141. doi: 10.1016/j.procbio.2008.09.016

Tunlid, A., Schultz, N. A., Benson, D. R., Steele, D. B., and White, D. C. (1989). Differences in fatty acid composition between vegetative cells and N2-fixing vesicles of Frankia sp. strain CpI1. Proc. Natl. Acad. Sci. U.S.A. 86, 3399-3403. doi: $10.1073 /$ pnas.86.9.3399

Uyeda, M. (2003). Fattiviracins, antiviral antibiotics produced by an actinomycete. Actinomycetologica 17, 57-66. doi: 10.3209/saj.17_57

Uyeda, M., Yokomizo, K., Miyamoto, Y., and Habib, E. (1998). Fattiviracin A1, a novel antiherpetic agent produced by Streptomyces microflavus Strain No. 2445. I. Taxonomy, fermentation, isolation, physico-chemical properties and structure elucidation. J. Antibiot. 51, 823-828. doi: 10.7164/antibiotics.51.823

Vasileva-Tonkova, E., and Gesheva, V. (2005). Glycolipids produced by Antarctic Nocardioides sp. during growth on n-paraffin. Process Biochem. 40, 2387-2391. doi: 10.1016/j.procbio.2004.09.018

Vergne, I., and Daffé, M. (1998). Interaction of mycobacterial glycolipids with host cells. Front. Biosci. 3, d865-d876.

Vilhena, C., and Bettencourt, A. (2012). Daptomycin: a review of properties, clinical use, drug delivery and resistance. Mini Rev. Med. Chem. 12, 202-209. doi: $10.2174 / 1389557511209030202$

Vollbrecht, E., Heckmann, R., Wray, V., Nimtz, M., and Lang, S. (1998). Production and structure elucidation of di-and oligosaccharide lipids (biosurfactants) from Tsukamurella sp. nov. Appl. Microbiol. Biotechnol. 50, 530-537. doi: $10.1007 / \mathrm{s} 002530051330$ 
Walter, V., Syldatk, C., and Hausmann, R. (2010). "Screening Concepts for the Isolation of Biosurfactant Producing Microorganisms," in Biosurfactants. Advances in Experimental Medicine and Biology, Vol. 672, ed R. Sen (New York, NY: Springer), 1-13.

Wang, W., Shao, Z., and Cai, B. (2014). Oil degradation and biosurfactant production by the deep sea bacterium Dietzia maris As-13-3. Front. Microbiol. 5:711. doi: $10.3389 /$ fmicb.2014.00711

Watanabe, R., Yoo, Y. C., Hata, K., Mitobe, M., Koike, Y., Nishizawa, M., et al. (1999). Inhibitory effect of trehalose dimycolate (TDM) and its stereoisometric derivatives, trehalose dicorynomycolates (TDCMs), with low toxicity on lung metastasis of tumour cells in mice. Vaccine 17, 1484-1492. doi: 10.1016/S0264-410X(98) 00367-3

Weeks, O., and Andrewes, A. (1970). Structure of the glycosidic carotenoid corynexanthin. Arch. Biochem. Biophys. 137, 284-286. doi: 10.1016/00039861(70)90435-2

Yeh, M.-S., Wei, Y.-H., and Chang, J.-S. (2005). Enhanced production of Surfactin from Bacillus subtilis by addition of solid carriers. Biotechnol. Prog. 21, 1329-1334. doi: 10.1021/bp050040c

Yokomizo, K., Miyamoto, Y., Nagao, K., Kumagae, E., Habib, E., Suzuki, K., et al. (1998). Fattiviracin A1, a novel antiviral agent produced by Streptomyces microflavus strain No. 2445. II. Biological properties. J. Antibiot. 51, 1035-1039. doi: 10.7164/antibiotics.51.1035

Yu, G., Hu, Y., Hui, M., Chen, L., Wang, L., Liu, N., et al. (2014). Genome shuffling of Streptomyces roseosporus for improving daptomycin production. Appl. Biochem. Biotechnol. 172, 2661-2669. doi: 10.1007/s12010-0130687-z
Yu, G., Jia, X., Wen, J., Lu, W., Wang, G., Caiyin, Q., et al. (2011). Strain Improvement of Streptomyces roseosporus for daptomycin production by rational screening of He-Ne laser and NTG induced mutants and kinetic modeling. Appl. Biochem. Biotechnol. 163, 729-743. doi: 10.1007/s12010-010-9078-x

Zajic, J. E., Gignard, H., and Gerson, D. F. (1977). Properties and biodegradation of a bioemulsifier from Corynebacterium hydrocarboclastus. Biotechnol. Bioeng. 19, 1303-1320. doi: 10.1002/bit.260190905

Zaragoza, A., Aranda, F. J., Espuny, M. J., Teruel, J. A., Marqués, A., Manresa, A., et al. (2009). Mechanism of membrane permeabilization by a bacterial trehalose lipid biosurfactant produced by Rhodococcus sp. Langmuir 25, 7892-7898. doi: 10.1021/la900480q

Zhi, X.-Y., Li, W.-J., and Stackebrandt, E. (2009). An update of the structure and $16 \mathrm{~S}$ rRNA gene sequence-based definition of higher ranks of the class Actinobacteria, with the proposal of two new suborders and four new families and emended descriptions of the existing higher taxa. Int. J. Syst. Evol. Microbiol. 59, 589-608. doi: 10.1099/ijs.0.65780-0

Conflict of Interest Statement: The authors declare that the research was conducted in the absence of any commercial or financial relationships that could be construed as a potential conflict of interest.

Copyright (C) 2015 Kügler, Le Roes-Hill, Syldatk and Hausmann. This is an openaccess article distributed under the terms of the Creative Commons Attribution License (CC BY). The use, distribution or reproduction in other forums is permitted, provided the original author(s) or licensor are credited and that the original publication in this journal is cited, in accordance with accepted academic practice. No use, distribution or reproduction is permitted which does not comply with these terms. 